\title{
ON READING THE TRACTATUS RESOLUTELY
}

\author{
Reply to Meredith Williams and Peter Sullivan
}

\author{
James Conant and Cora Diamond
}

\section{Introductory remarks}

Wittgenstein gives voice to an aspiration that is central to his later philosophy, well before he becomes later Wittgenstein, when he writes in $\$ 4.112$ of the Tractatus that philosophy is not a matter of putting forward a doctrine or a theory, but consists rather in the practice of an activity - an activity he goes on to characterize as one of elucidation or clarification - an activity which he says does not result in philosophische Sätze, in propositions of philosophy, but rather in das Klarwerden von Sätzen, in our attaining clarity in our relation to the sentences of our language that we call upon to express our thoughts. ${ }^{1}$ To say that early Wittgenstein already aspired to such a conception of philosophy is not to gainsay that to aspire to practice philosophy in such a manner and to succeed in doing so are not the same thing. It is therefore not to deny that, by Wittgenstein's later lights, the Tractatus is to be judged a work that is marked by forms of failure tied to its having failed fully to live up to such an aspiration. But if it is thus to be judged, then it is to some degree a failure even by Wittgenstein's own earlier lights. This means that if one wants to understand the fundamental turn in Wittgenstein's thinking as he moves from his earlier to his later philosophy, and why it is that he wanted the Tractatus to be published and read together with Philosophical Investigations, one needs to understand what sort of failure this is - and that requires coming to terms with the Tractatus's own understanding of what sort of work it was trying to be. We think that readers of the Tractatus - be they admirers or detractors of Wittgenstein - have, on the whole, failed to do this.

In our own efforts to try to do this, we have been led to a way of reading the Tractatus that has come to be known as 'resolute'. ${ }^{2}$ Most criticisms of resolute readings of the Tractatus are meant to show that, despite the attractions of such readings, the standard sort of reading is preferable. This has led to a controversy in which both critics and fans of such a resolute way of reading the book have 
tended in their attacks and defenses to speak of 'the resolute reading'. ${ }^{3}$ Though the word 'resolute' is not a term either of us originally employed to characterize our manner of reading the Tractatus, we are happy to accept it as aptly encapsulating certain general features of our reading. But it is important to see that the features of a reading that make it appropriate for it to be thus characterized are of quite a general nature, sufficiently so as to leave a great many questions about just how the Tractatus ought to be read in detail unanswered. There is no reason why there should not be a variety of resolute readings. Indeed, as more and more scholars of Wittgenstein's work come to find themselves dissatisfied with the standard sort of reading, and especially now that some of them are also drawn to the possibility of a resolute alternative - and as our own continuing attempts, partly prompted by this recent explosion of work on the Tractatus, to think through our earlier suggestions about how to read the book have led us to reformulate and sometimes rethink some of the details of our own reading - it is becoming evident not only that a variety of resolute readings is possible, but that Tractatus scholarship is entering a stage in which that possibility is actual. ${ }^{4}$

So a resolute reading is better thought of as a program for reading the book, and not only for the reason just given (namely, that a variety of such readings is possible) but also because conformity to the basic features of such a reading leaves undetermined exactly how a great deal of the book works in detail. To be a resolute reader is to be committed at most to a certain programmatic conception of the lines along which those details are to be worked out, but it does not deliver a general recipe for reading the book - a recipe that one could apply to the various parts of the book in anything like a straightforward or mechanical way. ${ }^{5}$ And we do not apologize for this. For we think that this is just how it should be. There should be no substitute for the hard task of working through the book on one's own. A resolute reading does not aim to provide a skeleton key for unlocking the secrets of the book in a manner that would transform the ladder into an elevator; so that one just has to push a button (say, one labeled 'austere nonsense') and one will immediately be caused to ascend to Tractarian heights, without ever having to do any ladder-climbing on one's own.

There are two interrelated general features that suffice to make a reading 'resolute', in the sense of that term that we are concerned with here. The first is that it does not take those propositions of the Tractatus about which Wittgenstein said, at $\$ 6.54$, that they are to be recognized as 'nonsensical' to convey ineffable insights. ${ }^{6}$ The second feature is a rejection of the idea that what such recognition requires on the part of a reader of the Tractatus is the application of a theory of meaning that has been advanced in the body of the work - a theory that specifies the conditions under which a sentence makes sense and the conditions under which it does not. (Notice: both of these features of a resolute reading say something about how the book ought not to be read, thereby still leaving much undetermined about how the book ought to be read.) Taken together, these features rule out two central interrelated features of the (standard) sort of reading, according to which the truths of the theory supposedly advanced in the 
body of the book prescribing what can and cannot make sense are themselves supposed to be necessarily ineffable.

It is a corollary of the second of these features that a resolute reading is committed to rejecting the idea that the Tractatus holds that there are two logically distinct kinds of nonsense: the garden-variety kind (cases of which we are able to identify prior to our initiation into the teachings of the Tractatus) and a logically more sophisticated kind (the nonsensicality of which is due to their logically internally flawed character). Resolute readings are committed to rejecting not only various previously fashionable accounts of the details of Wittgenstein's putative theory of why the sentences of philosophers are afflicted with a special sort of nonsensicality, but also any subsequent account that attributes to the author of the Tractatus an indefeasible commitment to a theory of this sort. From the vantage of a resolute reader, it makes little difference whether the account given of the supposed theory be one that rests on an appeal to verifiability, bipolarity, logical syntax, or some other putative respect in which 'philosophical propositions' are to be identified as nonsensical because of having been put together in some special kind of logically or conceptually illegitimate manner. All such accounts will qualify equally as instances of an irresolute reading, if they are committed to ascribing to the Tractatus a theory which its author must endorse and rely upon (if he is to be able to prosecute his program of philosophical critique) and yet which he must also regard as nonsense (if he thinks through the commitments of his own theory). ${ }^{7}$

Many critics of resolute readings notice that resolute readers are committed to one or another of the corollaries of this second feature, without ever managing to get this second feature itself clearly into view. Such critics notice that resolute readers are committed to rejecting some particular putatively Tractarian account of what makes some sentences nonsensical (say, an account based on illegitimate syntactical combination), while assuming that a resolute reader must share with the proponent of a standard sort of reading the idea that the charge of nonsense leveled at the end of the Tractatus is to be underwritten by some theory - be it one that is advanced within the body of the work or one that is imported into the work from the outside. These critics thereby assume that resolute readers must want to substitute some alternative theoretical account of the grounds of sense for the particular one under criticism. ${ }^{8}$ These critics then become understandably very puzzled about how a resolute reading can possibly be thought to be sustainable. For they assume that the discovery that there are no logically distinct kinds of nonsense is itself arrived at through the elaboration and application of a theory of sense that resolute readers are now committed to viewing as having somehow been successfully articulated by the author of the Tractatus, even though the propositions by means of which it is to have been articulated have been relegated to the status of mere nonsense. This then leads to the criticism that a resolute reading renders the propositions of the book too semantically impoverished to be able to articulate the theoretical conceptions about the nature of nonsense that resolute readers are committed to ascribing to the work. 
Whatever one thinks of the project of trying to read the Tractatus resolutely for there are a variety of grounds on which one might want to oppose such a reading ${ }^{9}$ - it is important to come to see that the preceding sort of criticism misses the mark. A resolute reading does not take Wittgenstein's aim in the book to have been the communication of a theory of meaning, a theory of logic, or any other theory. The sort of resolute reading that we accept rather takes as central Wittgenstein's ideas about clarification as the aim of philosophy. Our understanding of this aim hangs together with 'resolution', in that we take clarification not to be something that the author of the Tractatus sought to achieve through the putting forward of effable or ineffable doctrines. In our replies to both Meredith Williams and Peter Sullivan below, we will attempt to bring out how we take the author of the Tractatus to have conceived clarification to be possible in the absence of a commitment to such doctrines. ${ }^{10}$

\section{Reply to Meredith Williams's defense of standard readings}

Any comparison of the resolute and standard sorts of reading of the Tractatus, of the sort which Williams wishes to make, must show awareness of what the problems may be thought to be with each of the two types of reading, since it is hardly possible to convince anyone of the superiority of one sort of approach if one ignores or plays down the problems with that reading. Here it matters both that Williams's account of what is involved in a resolute reading of the Tractatus is inaccurate and that she does not seriously confront the problems inherent in the standard sorts of approach. We shall consider both of these points. We shall address some of the problems with the standard approach first. We shall take up some of Williams's criticisms of resolute readings in section 3.

The most fundamental problem with the standard approach to reading the book lies in its, on the one hand, wanting to take the content of the charge of nonsense to be underwritten by a theory that is advanced within the body of the book, and on the other hand, wanting to take the charge of nonsense to apply to the propositions that articulate that theory. If the propositions articulating the theory which is to entitle us to conclude that certain other propositions are nonsense are themselves nonsense, then that would appear to undercut our entitlement to the conclusion. If we really come to see that the propositions that comprise the theory are nonsense, then are we not thereby also obliged to concede that those propositions fail to furnish us with adequate grounds for believing in the truth of the theory, or for that matter in anything else? This problem gives rise to the dilemma at the heart of standard approaches to the book: either (1) one must tell a story that waters down what it means to say of the propositions of the work that they are 'nonsense' or (2) one must accept the characterization of these propositions as nonsense at face value. If a proponent of the standard reading seizes the first horn of the dilemma, then he may well be able to appear to furnish himself with resources for allowing enough light into his story about 
what it is for something to be nonsense so that it can now appear to be the case that someone can, after all, 'grasp' what is 'meant' by a nonsensical proposition. The only problem then is that much of what is originally advertised as original in the doctrines of the Tractatus (e.g. about the relation between the limits of thought and the limits of language) either turns out to be false (because it turns out we can, after all, think all kinds of things that cannot be said) or to be reinterpreted in a manner that renders those doctrines vacuous (because terms such as 'nonsense', 'showing', etc., turn out to be mere façons-de-parler for designating ways in which perfectly intelligible - and therefore only 'strictly speaking' nonsensical - propositions can be employed to communicate apparently perfectly expressible truths). If a proponent of the standard reading firmly seizes the second horn of the dilemma, and tries to hold on to the thought that nonsense is nonsense, then she is faced with the problem that the lights will threaten to go out on her enterprise as she conceives it: the theory in question (that she takes it to be the central concern of the work to advance) will turn out not really to be intelligible, after all. Given the unattractive consequences that attend seizing either of the horns of this dilemma, perhaps it is not surprising that what we are most frequently offered, instead, is a sort of 'reading' of the book that hovers between the horns, wanting to take to heart the idea that certain things cannot be said, but also wanting to tell us what it is that cannot be said, and why, where the reasons why are themselves held to be unsayable.

Proponents of the standard sort of reading will sometimes acknowledge that their reading faces some such difficulty, but they will then transfer the blame to the author of the Tractatus. 'I am not denying that the Tractatus is an incoherent work,' they will say, 'but don't blame me, blame Wittgenstein! And, after all, he eventually came to see himself that it was a failed work. Does this not provide evidence that something like my reading must be right?' Williams introduces a new wrinkle to this line of defense by appealing to Philosophical Investigations $\$ 110$ for support for a reading of the Tractatus that finds that work to exhibit a significant degree of tolerance for contradiction. She says that, in his later work, Wittgenstein identifies toleration of contradiction as indicating that one is in the grip of a picture. But the passage she cites does not say or imply anything about tolerance of contradiction. ${ }^{11}$ Wittgenstein was a man of quite exceptionally high standards, throughout his life, when it came to carrying through a line of thought which might appear to run into difficulty; he was not at any point a willing tolerator of inconsistency or logical mess. ${ }^{12}$ It might be suggested that the inconsistencies ascribed to Wittgenstein by those who give a standard reading of the Tractatus were ones of which he was not aware, because he was in the grip of a picture. But the inconsistencies and logical messes which we are going to describe below are not of a sort which it seems likely that early Wittgenstein would have been able to overlook simply in virtue of his being 'in the grip of a picture'. ${ }^{13}$ If you are in the grip of a picture, you may indeed construe every case as fitting the picture, even when it may seem obviously not to do so, as in Wittgenstein's example, from 1939, of someone who is committed to the idea 
that everyone in Cambridge has a telephone, and who construes absences of telephones as presences of invisible phones. ${ }^{14}$ That sort of interpretation of everything as fitting one's picture can account for a number of features of Wittgenstein's early thought, such as his treatment of all inference as truth-functional. But the picture of inference as truth-functional would not, for example, have enabled him to construe the meaningless sentences of the Tractatus as standing in logical relations of a truth-functional character. If he had taken the book to provide logically structured argument and his sentences to stand in logical relations, his account of logic would have been in a sort of trouble that no 'picture' would have enabled him to gloss over. We do not wish to deny that later Wittgenstein did come to view the author of the Tractatus as in various ways in the grip of a philosophical picture. But we do wish to urge that anyone who is in too much of a hurry to rely on this bit of knowledge about later Wittgenstein in advancing a reading of his early book is bound to evade the real difficulties that lie in the path of coming to see what it was that early Wittgenstein took himself to be trying to do in the Tractatus.

To claim that Wittgenstein's own later view of the author of the Tractatus as in the grip of a picture cannot satisfactorily account for the sorts of confusion attributed to that book by Williams is, however, not to deny that a philosopher far less careful and acute than Wittgenstein might well be prey to a picture of a sort that would allow him to fall into just these sorts of confusion. Someone might picture 'the limits of logical thought' in quasi-geometric terms, imagining such limits on the model of the limits of a geographical territory (and therefore as a region of space that has an inside and an outside); so that just as there is something which is traversing the limit (and thus moving into the region which lies beyond the territory circumscribed by the limit), so, too, there must be something which counts as transgressing 'the limits of thought' (and thus thinking outside or beyond the region of thinking 'circumscribed' by the laws of logic). ${ }^{15}$ But to be in the grip of that sort of a picture requires not merely glossing over but completely jettisoning many of the characteristic commitments of Wittgenstein's early thought. ${ }^{16}$ The kind of incoherence to be found in Wittgenstein's early philosophy on the standard reading is therefore not really explicable by appeal to the idea that he was in the grip of a picture and saw everything in the terms provided by the picture. Such an appeal can seem to alleviate the sort of trouble the standard reading allows itself to discover the Tractatus in, only if one, in effect, ceases to take seriously the thought that early Wittgenstein was, after all, early Wittgenstein.

According to Williams's brief summary of the standard reading, Wittgenstein in the Tractatus 'tolerates paradox', in particular, by putting forward in the book a theory of meaning that 'undercuts the meaningfulness of the sentences used to state that theory'. He uses, she says 'the doctrine of showing to ameliorate its irrationality'. In that statement and in Williams's earlier summary of the standard sort of reading, there is a failure to distinguish between, on the one hand, the showing which is spoken of in the Tractatus (where 
senseful propositions, tautologies and contradictions are said to show things, but nonsensical propositions are not spoken of as showing anything) and, on the other, the supposed conveying of ineffable insights by the propositions of the Tractatus itself. We shall turn below to the question what a resolute reading can make of 'saying versus showing'. But what any satisfactory reading must do is not run together the showing done by senseful propositions, tautologies and contradictions with the 'illuminating' supposedly done by the propositions of the Tractatus itself. ${ }^{17}$ If a reader of the Tractatus believes that showing, in the sense in which that term (i.e. the term zeigen) occurs in the Tractatus, is relevant to the question how sentences taken to be neither senseful nor tautologies nor contradictions can illuminate anything, that needs to be explained; but Williams does not seem to see that there is a problem here. There are versions of the standard reading that do not blur the distinction between showing, as that term is applied to senseful propositions, tautologies and contradictions, and the supposed conveying of illumination about things which cannot be said by the propositions of the Tractatus. Any hope of attaining clarity concerning the difficulties confronted by various versions of the standard reading requires, at a minimum, that no assumption be made that 'the doctrine of showing' somehow carries with it an account of how the propositions of the Tractatus are able to do what they are supposed to - an account of what it is for a book of propositions which do not say anything to communicate something nevertheless. There is no obvious connection between what senseful, tautologous and contradictory propositions do (when they show what they do) and anything that those propositions that we are eventually to recognize as nonsensical can be said to do (the Tractatus says they elucidate) - that is, there is no obvious connection of the sort that Williams implies is readily available. ${ }^{18}$

She wants to describe resolute readers as accepting a thesis about the Tractatus that it is consistent but point-missing, while standard readings are willing to accept a degree of paradox in the way in which the book is supposed to work - a degree of paradox that makes it a more interesting book. They are willing to accept that there is this irremediable paradox involved in the capacity of the book to communicate anything - a capacity supposedly tied to the doctrine of showing - because it supposedly makes better sense of the book as a whole. But her description, involving as it does an unexplained reference to work supposedly done by the 'doctrine of showing', is not so much a description of a book with paradox at its core as it is a description of a book with a big gap at its center - a gap which cannot be papered over or otherwise concealed by invoking 'the doctrine of showing'. For what Wittgenstein says about showing in the Tractatus has no obvious or direct application to those propositions of his book that are not senseful, tautologous, or contradictory. If the remarks in the book that speak of 'showing' are supposed indirectly to account for the communicative power of the propositions of the book that are to be recognized as nonsensical (but which do not show anything in the sense in which Wittgenstein speaks of 'showing'), how they do it is, for all Williams says, a total mystery. ${ }^{19}$ 
Suppose, however, we consider, for a moment, standard readings of the Tractatus that do not blur the issues here in the way Williams blurs them. There is still a question, for any version of the standard reading, about the way in which Wittgenstein thought his sentences worked - the way in which they were supposed to convey the insights that (according to this sort of reading) he intended them to convey. If one has a sentence $\mathrm{S}$, which is meaningless and which is supposed (alone or together with other meaningless sentences) to convey some particular insight I, there presumably has to be some connection between the words actually used in $\mathrm{S}$ (and the other meaningless sentences) and its being I, and not some other insight, that is supposed to be conveyed. If Wittgenstein's supposed theory of meaning disallows the meaningfulness of $\mathrm{S}$, is there some further view that can be ascribed to him which would make it at least plausible that he took sentences that were not meaningful to be capable of conveying insights in a way that depended on what the sentences themselves were? But any kind of system for reading such sentences (or in some other way extracting insights from them) would appear to explain in what way they were meaningful, and thus would not be consistent with regarding them as meaningless. ${ }^{20}$ If Wittgenstein is supposed to have thought that specific sentences of the Tractatus conveyed specific insights, in such a way that different people should in principle be able to grasp the same insight from any specific insight-conveying sentence, but is supposed not to have had any idea at all about how this conveying of insights worked, what sort of paradox would that be? It would simply be a case of failure to think about a very obvious problem. Alternatively, if Wittgenstein is supposed to have had some idea (even a rough and general sort of idea) about how the sentences were to be read as conveying specific insights, dependent on the structure and wording of the sentences, such an idea would appear to be straightforwardly inconsistent with views which even standard readings ascribe to the Tractatus. If this straightforward inconsistency is in no way addressed, then what we have is not an interpretation which makes his views 'paradoxical' but one which makes them just plain incoherent. But, if it is to be addressed, it is by no means clear how this might be done; it is not clear that there is any available account that would not ascribe to Wittgenstein views of a sort that he was himself concerned to reject.

Williams, along with many other proponents of the standard sort of reading, is not averse to ascribing a considerable degree of inconsistency to Wittgenstein; but one ought to be averse to making the book out to involve plain failure to deal with such an obvious problem as how meaningless sentences might convey specific insights. If specific sentences are not in some way tied down to specific insights then, in truth, there is no such thing as the standard reading. For such a reading requires not just that there be a right way to grasp the Tractatus propositions and to connect them with insights, despite their meaninglessness, it requires also that Wittgenstein took there to be a right way to grasp his propositions and connect them with insights, despite their meaninglessness. ${ }^{21}$ In some of our papers on the Tractatus we have canvassed a number of proposals previous 
commentators have put forward about how to connect specific meaningless propositions with specific insights and discussed the difficulties - both exegetical and philosophical - that such proposals tend to run into. Williams manages to avoid such difficulties altogether by leaving it utterly vague how, according to her take on the Tractatus, particular bits of nonsense are to be correlated with and convey particular insights. But, without some proposal in place for how to get around this problem, it hard to see how one can go about assessing the relative merits of the 'reading' on offer.

There are other deep problems with the standard readings that go unmentioned by Williams. It would take us well beyond the appropriate scope of this reply to go into all of them. We will conclude this part of the paper by simply mentioning some further problems and reminding the reader of some of the parts of Wittgenstein's text that Williams does not discuss (but that should matter) in assessing the relative merits of resolute readings.

A first such problem is that the theory of meaning that the book is taken to express must have consequences not only for the topic of the meaningfulness of the sentences that are used to argue for and express the theory, but also for a great many other of the tightly intertwined topics of which the book treats. If we suppose, with the standard sort of reading, that the book does put forward such a theory, the theory would have consequences not just for what can be said but also for what can be thought, ${ }^{22}$ for what can be grasped or understood, ${ }^{23}$ for what can be conveyed, etc. If a consequence of the supposed theory is that the sentences of the book are nonsensical, a further consequence would appear to be that anything that the sentences might at first be taken to convey is not graspable, including the supposed theory of meaning. To take Wittgenstein to have intended his book to convey certain insights, including a theory with the supposed consequence that the insights in question cannot be grasped (that there is no such thing as thinking them), is not to describe Wittgenstein as willing to put up with 'paradox'; it is to leave yet another big gap in the center of one's reading. If the 'doctrine of showing' is supposed to fill the gap, this needs to be explained. The interpretation would need to spell out how one might get from the 'showing' done by senseful propositions to the graspability of the supposed insights conveyed by the nonsensical sentences of the book. Without such an account, it will not be clear whether a reading of Wittgenstein with any plausibility can be given along the lines that Williams suggests. Some proponents of the standard sort of interpretation have struggled valiantly with this sort of problem, but their struggles tend to run into characteristic and unsatisfying sorts of dead-end (which we and other resolute readers have documented and discussed at considerable length elsewhere). Williams offers no indication of how she would address the problems that such accounts face. But absent some concrete suggestions about how to make the Tractatus's treatments of topics such as saying, thinking, understanding, etc., hang together as a coherent whole, there must remain some question as to whether the proffered interpretation is to be regarded as being as clearly superior as she suggests it is. 
A second such problem, briefly touched on above, concerns the supposed theory of logic to which Wittgenstein is committed on standard readings. It is difficult to see how to square the claim that the propositions of the book are nonsense with the claim that those propositions are able to provide logically structured argumentation. Their providing such arguments is taken by standard readings to be an essential element in the way in which the book is meant to enable readers to reach the insights that it supposedly conveys. The standard reading depends, in its various versions, either on not confronting the problems here (this present one and the others to which the reading leads ${ }^{24}$ ) but stopping short wherever they crop up, or on ascribing to Wittgenstein a quite uncharacteristic failure to take seriously the problems to which his views would plainly lead on the standard reading, or on an un-worked out idea about how an appeal to 'showing' contains some sort of solution to these problems, and frequently on some combination of these strategies. One therefore does not have to accept some expository thesis of 'strong consistency', as Williams suggests, in order to arrive at the view that standard readings are deeply problematic. There have to be limits, on any reasonable understanding of what is involved in exposition, on how logically problematic you can make a text by Wittgenstein out to be, where the problematic character in question would not have been hard for him to see, supposing him to have accepted the view ascribed to him. Standard readings in general understate or ignore the problems here.

The following bears repeating: taking Wittgenstein to have been in the grip of a picture, in the way Williams does, provides no account at all of why he might have been willing to tolerate the various sorts of problems mentioned above. They arise for anyone who accepts precisely the picture that is ascribed to Wittgenstein by the standard reading. These problems are salient, given that reading; they are not made invisible or tolerable through an acceptance of the picture of language that that reading ascribes to him. Critics of resolute readings that represent the state of play in Tractatus scholarship, as Williams does, as one in which a perfectly viable reading of that work has long been available and no reasons have yet to surface for not resting content with the previously prevailing status quo - critics, that is, who, in the light of the problems with standard readings that have been raised by resolute readers, are unwilling to reopen the question of their viability far enough at least to say something about how these problems are to be addressed - ask us, in effect, to assess the merits of a resolute approach to the book without ever really entering into the interpretative issues that give rise in the first place to the impulse to see if one might not be able to come up with a way of reading the book that makes these problems disappear. Such a blinkered approach to assessing the relative merits of alternative ways of reading the book is bound to generate more heat than light.

In concluding this part of the paper, it is worth noting that, in our above discussion, in stating these problems, we have entirely left to one side the many problems that arise if one goes on to take into account those portions of the text of the Tractatus that standard readings tend to underplay or brush entirely 
to one side. There are various sorts of passage that matter here, of which the following two are perhaps the least awkward to adduce without any further interpretative stage-setting: first, there are those passages in the text that would appear to repudiate precisely the view of nonsense on which the standard reading depends (most notably perhaps, §§5.473-5.4733); second, there are those moments where the author's way of characterizing his sentences and what a reader is to do with them would appear to conflict with the standard sort of reading (most notably perhaps, in the Preface and the concluding sections). One obvious instance of this sort is the remark in the Preface that 'what lies on the other side of the limit will be simply nonsense' (our emphasis). A more neglected, but equally striking instance of this sort is the author's speaking, in $\$ 6.54$, of his propositions as something we are meant to overcome. This seems to suggest, at any rate, that the road to 'paradox' and incoherence, which we take when we refuse to overcome the propositions but try instead to hold on to them as somehow managing to communicate ineffable insights, is not the road that Wittgenstein envisaged as the one the reader is to take if she is finally to arrive at the point (that forms the opening topic of §6.54) at which she understands the author of the book by having come to recognize his sentences as nonsensical.

There are numerous other sorts of passage in the text (that we and other resolute readers have highlighted in our writings) that put pressure on a standard sort of construal of the work as a whole. Someone with imagination and sympathy for the standard sort of approach may well be able to find ways to come to its aid and make something of these passages, giving reasons why Wittgenstein's text is worded in just the ways it ought to be at these junctures. We invite those with such sympathies to help push the debate forward by giving such reasons. And we will continue to try to make the best overall sense we can of those passages in the text that most confound us. Only through a combined effort of this sort will it be possible to achieve a fair assessment of the relative merits of these and other approaches to the text.

\section{Reply to Meredith Williams's criticisms of resolute readings}

We turn now to a discussion of some of Williams's central criticisms of resolute readings, and, in particular, to some of the inaccuracies in her remarks about resolute readings in general and about Diamond's views in particular. We will discuss these under four headings: (1) the 'you, too' objection, (2) the covert theory of nonsense objection, (3) the 'what about showing?' objection, and (4) the methodological objection. ${ }^{25}$ (We will mostly defer discussion of the 'strong continuity thesis' that Williams ascribes to us until section 5.) We are grateful to Williams for affording us this opportunity to clear up certain misunderstandings of our views, especially as there is every reason to think that these misunderstandings are not yet as uncommon as we would like to see them become. 


\section{The 'you, too' objection}

Williams frequently employs what we will call the 'you, too' argument. It is a central argument of hers and depends on a pervasive misunderstanding of what is involved in a resolute view of nonsense. The argument goes as follows: resolute readings, although they claim to avoid the kind of paradox which standard readings find in the Tractatus, are in fact no less committed to a reading that involves just this kind of paradox. The paradox, Williams argues, can be moved from one point to another but cannot really be diminished.

Let us begin with the following question: why does she think that any reading of the Tractatus will involve a commitment to paradox somewhere? The standard readings of the Tractatus locate paradox in the fact that Wittgenstein puts forward a theory of meaning in the book which has as its consequence that the propositions of the book are nonsensical; the response to the paradox ascribed by standard readings to Wittgenstein (according to Williams) is that Wittgenstein attempts to mitigate the paradoxicality by using the 'doctrine of showing' to explain the communicative power of his own propositions. (Her account fits only some standard readings; as we have noted, not all standard readings share Williams's willingness to muddle together the 'showing' of which Wittgenstein speaks and the conveying of insights by the propositions of the Tractatus.) According to Williams, resolute readings of the Tractatus equally depend on substantial philosophical commitments, on which they take Wittgenstein to draw. The resolute reading, too, takes Wittgenstein to accept a theory of what nonsense is; and it must be an account of nonsense powerful enough to be able to bring about a deconstruction of the text of the Tractatus. But, she thinks, on any reading, the philosophical commitments that underpin the view of nonsense must not themselves be taken to be undercut by the theory itself. Therefore something akin to a 'saying-showing' distinction (of the sort ascribed to Wittgenstein by standard readers) must be in play, she thinks, on any reading, if such commitments are to remain secure in the face of the book's attack on philosophical nonsense, including its own unmasking of the propositions of the Tractatus as nonsense. As Williams sees the 'saying-showing' distinction, what it does is enable some theses to serve as genuine bases for philosophical critique; the paradoxicality lies in the attempt to exempt from the critique some set of theses to which the critique would appear to be applicable. The standard reading (what she regards as the standard reading) takes the theses that escape full demolition to be expressed within the book; the resolute reading (what she takes to be the resolute reading) must, on her view, locate the theses that escape full demolition somewhere. There is no way to read the Tractatus which does not involve some such paradoxical willingness to cling to certain theses which underwrite a project of philosophical critique - theses that have been made exempt from the full blast of philosophical critique - even though the critique would appear to be applicable to them. So the only real difference between standard readings and resolute readings is in how each sort of reading identifies the theses in question 
and in what story they tell about why these theses in particular are exempt from the full blast of philosophical critique.

The 'you, too' argument rests on a fundamental misconception of what is involved in a resolute reading, and in the view of nonsense that forms part of it. One of the main sources of this misconception stems from her reading of certain isolated remarks in 'Throwing Away the Ladder'. ${ }^{26}$ She reads Diamond's view of nonsense to have at its heart the idea that sign-constructions are nonsensical if they violate certain specifiable conditions for being a sentence. She takes Diamond to hold that some sign-combinations, like 'What those view Paradise 5 between of', are nonsensical because they transparently fail to fulfill the relevant conditions. They transparently fail to have the appropriate sort of syntactic structure. And, supposedly, Diamond then holds that there are less obvious syntactic conditions on being a sentence which are violated by sentences like 'A is an object' and by the sentences of the Tractatus itself. The crucial condition is that of bipolarity: it is the failure to meet the bipolarity condition that explains (on Diamond's view as Williams presents it) why such sentences can be recognized to be nonsensical. Such a recognition is in fact a recognition that they are like 'What those view Paradise 5 between of' in being syntactic messes, although this is not obvious on the surface. This reading of Diamond is closely tied to Williams's argument that Diamond's reading, and other resolute readings, cannot dispense with paradox. For, if it is the case that Diamond is extracting, either from the Tractatus or from somewhere else, a theory of meaning which enables her to formulate general conditions which sentences must meet, such that sign-combinations can be recognized to be nonsensical through failure to meet those conditions, then indeed there is something puzzling or paradoxical at the heart of her reading. It looks as if she is dependent on a theory powerful enough to generate substantial claims about violations of essential conditions of meaningfulness, while at the same time trying to distance Wittgenstein from all substantial theorizing.

Here we come to one of the fundamental points in resolute readings, that we mentioned in section 1: resolute readings reject the idea that nonsense is the result of the violation of some or other kind of logical conditions on legitimate sentence-construction. Williams discusses in detail the example 'A is an object', and ascribes to Diamond the view that that sentence is nonsensical because if it is meaningful it would be necessarily true and hence would violate the bipolarity condition. Two things are wrong with this as an account of Diamond's view, or indeed of any other version of a resolute approach: (1) the ascribed account of nonsense rests on an appeal to features that sentences would have if they were meaningful; (2) the account is taken to rest at certain points on an appeal specifically to a principle of bipolarity.

1 You cannot establish the nonsensicality of a sentence by any appeal to features that it would have if it were meaningful. If a sentence is nonsensical, then, on the view of nonsense that forms a part of any resolute 
reading, it contains a word or words to which no meaning has been given. Meaning can be given to that sign in many different ways. What it would say if it were meaningful might be a million different things. To suggest that there is something you can get hold of which is what it would say if it were meaningful, something that is logically problematic in some way, and which would be at the root of the meaninglessness you would be able to go on to ascribe to the sentence, is to see in it some logically faulty sort of sense. This is exactly the approach rejected by both of us in our writings on the Tractatus. The approach is described by Diamond in her discussion of 'A is an object', ${ }^{27}$ but it is the approach that she is criticizing. The idea of there being something the sentence would mean if it meant anything is exactly what she treats as characteristic of a wrong approach to sentences like 'A is an object'. In the pages of hers (in 'Throwing Away the Ladder') that seem to have inspired Williams's reading of her, Diamond explicitly says that she has just presented a wrong account of Wittgenstein's view in her discussion of the idea that, given Wittgenstein's view of what sentences are, there must be a violation of conditions of meaningfulness by the sentence 'A is an object'. Discussions of the sort of approach to nonsense that Williams attributes to resolute readers figure equally in Conant's work, but, again, always only as a target (and never as the doctrine) of the work: 'The Tractatus does not aim to show us that certain sequences of words possess an intrinsically flawed sense by persuading us of the truth of some theoretical account of where to locate "the limits of sense".,28

2 We hold that you cannot establish the nonsensicality of a sentence or wouldbe sentence by establishing that it violates a condition of bipolarity. ${ }^{29}$ Suppose someone claimed that, from the recognition that a particular proposition lacked bipolarity, and was neither a tautology nor a contradiction, that it therefore had to be nonsensical, from the Tractatus point of view. The question then is: what supposedly lacks bipolarity? No mere sign has or lacks bipolarity. And, again, if we call something a tautology, we are taking it that the names in it have a particular use: if two occurrences of the same letter, say, are not names for the same thing, the sense cannot 'cancel out' as it does in a tautology. Take a typical Tractatus proposition, of the sort that appears to lack bipolarity, 'Propositions are truth-functions of elementary propositions.' What use do we want to give the first word of that proposition, as it occurs there? It is hardly meant to refer to all things that look like propositions. Nor do we intend to use the word 'propositions' to mean truthfunctions of elementary propositions; we don't want to use the quoted propositional sign to say that truth-functions of elementary propositions are truth-functions of elementary propositions. In order to make this Tractatus proposition out as lacking bipolarity, and as not being a mere tautology, we should have to specify some other sort of use for that first word. If there is no specifiable use that we will accept as what we want there, we can recognize a kind of failure, but it is a failure to give any meaning to one of the 
words we are using. The idea we may have, that 'absence of bipolarity' might be directly available to us as we consider a proposition, comes from failure to take seriously that a sign does not itself determine a use. We have to make clear that use of the propositional sign such that we want to say: the sign used that way expresses something that is not bipolar. Before there is any attempt to apply some general doctrine about non-bipolar propositions, we've got to have such a proposition. But what will happen if we attempt to spell out the use we mean is that the attempt at clarification will show us that there is nothing we will accept as what we mean. The attempt at clarification has to precede the supposed application of doctrine; and, if indeed the proposition-like thing in question is philosophically problematic, what will happen is that the attempt will bring out a kind of failure to mean anything clear at all. We shall never get as far as the supposed application of doctrine. What does the work is the attention to the particular problematic sentence itself, the attempt to clarify it, and the failure of that attempt. ${ }^{30}$

You can try to show that a sentence is nonsensical by trying to clarify it, and revealing in the course of that attempt that there is some word or words in it to which the person uttering the sentence (who may indeed be yourself) has given no determinate meaning. But the absence of meaning is not something that can be inferred in an argument from some criterion of logical illegitimacy. On our view of the Tractatus, we are not supposed to derive from some theory of meaning (or from anything else) conditions of logical legitimacy of some sort, violation of which would put us into a position to infer nonsensicality or to infer that some word or words in a sentence lacked meaning. As we read the Tractatus, no combination of signs that we can put together can be faulted on grounds of logical illegitimacy. If 'Socrates Plato' has no meaning, the reason is that we have not given meaning to the fact that 'Socrates' stands to the left of 'Plato' (that one name stands to the left of another). We could do so. (Question: 'Who taught whom?'; answer: 'Socrates Plato.') There is no logical condition that is violated by 'Socrates Plato', or even by 'Socrates Abracadabra'. ${ }^{11}$ Any string of signs can be taken to be a fact in various ways; and that those signs stand in these or those relations can then be taken to signify this or that. They do not, messy as they may look, violate any conditions in such a way as to allow us simply to conclude that they are nonsensical; we cannot conclude that, because of some supposedly specifiable violation, the signs thus related cannot be meaningful. (§5.4732: 'We cannot give a sign the wrong sense.')

It is central to our reading of Wittgenstein that he did not think that any combination of signs could be held, as such, to be logically illegitimate. He says that, if a sign is possible, it is also capable of signifying. When he says (at $\S 5.473)$ that, in a certain sense, we cannot make mistakes in logic, one of the things he means is that we cannot diagnose nonsense by picking out violations, by some combination of signs, of conditions for being a sentence, for meaning anything. There is no way to arrive at a diagnosis of a sentence as nonsensical 
by deriving from the Tractatus (or from anything outside the Tractatus, but accepted by Wittgenstein in the Tractatus) some conditions for being a sentence, and then noting that some sentence fails to meet those conditions. In particular, there is no way to arrive at a diagnosis of a sentence as nonsensical by deriving from the Tractatus a condition that sentences, if they are not to be nonsensical, must be bipolar, tautologies or contradictions. The view of nonsense that we ascribe to Wittgenstein does not depend on a theory of meaning that seeks to establish conditions for meaningfulness that could be thus employed in diagnosing nonsensicality. ${ }^{32}$

Williams also ascribes to Diamond the view that 'A is an object' can be shown to be nonsense by a perspicuous analysis, which would reveal it as having the form ' $(\exists x) A$ ', and thus to be transparently nonsense. Williams's account here is hard to follow, and does not correspond to anything Diamond has held. (It also does not appear to be consistent with the view that she ascribes to Diamond that we have just discussed: for if I write on the blackboard ' $(\exists x) A$ ', I can hardly be held to have written something that, if it were meaningful, would be necessarily true and supposedly therefore a violation of a bipolarity condition. It should be quite obscure, by anyone's lights, in such a case to speak of what this string of signs would mean 'if it were meaningful'.) There is indeed a use of the word 'object', as a formal-concept word, in which it corresponds to a use of the quantifier-variable notation. Thus 'An object fell' goes over to ' $(\exists \mathrm{x})(\mathrm{x}$ fell)', unlike 'A tortoise fell', which goes over to ' $(\exists \mathrm{x})(\mathrm{x}$ is a tortoise and $\mathrm{x}$ fell).' But someone who says 'A is an object' would appear to be using 'object' in a different way, namely as an ordinary predicate, like 'tortoise'. 'A is a tortoise' goes over to 'Tortoise (A)'; and it may seem that someone who says 'A is an object' wants to utter something which will go over into logical notation in the way that 'A is a tortoise' does. There is nothing whatever the matter with that. 'Object' can indeed be used as an ordinary predicate: we can certainly say of someone that he is an object, meaning (perhaps) that he is contemptible, or beneath contempt; or, alternatively that if we drop him out the window he will fall at 32 feet per second per second. The problem with the philosophical utterance of ' $\mathrm{A}$ is an object' is not that it somehow combines an existential quantifier with a name. ${ }^{33}$ The problem is rather that what the meaning of 'object' is supposed to be when used in a way that appears to be meant to parallel 'tortoise' has not been made clear. It's not clear what predicate-meaning the utterer wants it to have, if any. That does not say that it cannot be made clear, or that the sentence cannot make sense. It can. But someone who utters 'A is an object' may have two desires which appear to be able to coexist because they are not brought fully to awareness: she may want to use 'object' so that it is the ordinary-language term for a logical kind, in which case it would go over in logical notation to a combination of quantifier and variable, and she may also want to use it in a way that is parallel to 'tortoise' in 'A is a tortoise'. (The latter desire comes out in the form of words she uses; the former is involved in the failure to notice that the word 'object', in her use of it as predicate, has been given no meaning.) We are familiar in ordinary critical thinking 
with procedures in which such unclarity is brought to a person's notice. Thus, an equivocation involving 'or' in ordinary English might be brought to the speaker's notice, if he spoke Latin, by asking whether he wanted to translate what he said with aut or with vel; or, if he had been taught a logical notation, exactly the same clarification could be effected using the notation. It is important here that, if a person says 'A is an object' without definitely wanting to use 'object' either as a formal-concept word or as a predicate but is vaguely and confusedly hovering between both uses, the sentence has no translation into a formal notation. It would hardly translate into ' $(\exists \mathrm{Ex}) \mathrm{A}$ '. Confusions don't have translations into logical notation, any more than does a vague hovering between inclusive and exclusive 'or'. The elucidatory insight that logical notation can help us attain, for early Wittgenstein, comes not through our coming to see how what a sentence 'says' goes into the notation in the wrong way (because it has a logically flawed sense), but rather through our coming to see how 'it' (i.e. what we imagine the sentence to be trying to say) fails to go into the notation at all (because there is nothing determinate that we are here imagining).

So what we have seen thus far is the following: in her deployment of the 'you, too' argument, Williams ascribes to Diamond the idea that a philosophical sentence can be shown to be nonsensical through its violating certain conditions on meaning - that, once certain stipulations of meaning are in place, the resulting combinations of words are such that they cannot be given a logically permissible sense. The only reason for thinking that Diamond believes in such a 'cannot' would be the ascription to her of the idea that philosophical sentences violate some or other condition for meaningfulness. But, as we have noted, it is central in all resolute readings that nonsensical sentences are not rendered nonsensical by violating of conditions for meaningfulness, and, as we have seen, Williams's supposed textual evidence that Diamond holds otherwise is based on a misreading of Diamond's remarks. The supposed 'dilemma' for resolute readings that Williams presents depends on failure to grasp this central point. We turn now to the second misconception on which her argument depends.

\section{The covert theory of nonsense objection}

Independently of ascribing a particular theory of nonsense to Diamond, Williams is concerned to argue, as we have seen, that even if we resolute readers do not think we rely upon such a theory, in fact, we do, too. It is not unlikely that she will read through our discussion above of why the 'you, too' argument involves a misreading of Diamond and come to the following conclusion: 'OK, maybe they really do think they can do without a theory of nonsense here. But, of course, they cannot. In order to charge someone with speaking nonsense, you have to presuppose a theory of nonsense.' Williams fails here to see how deep our break with standard readings is meant to be. Standard readings of the Tractatus have at their heart the idea that Wittgenstein intended, in the Tractatus, to put forward a metaphysical conception of language and thought in relation to 
the possibilities of the world; and their commitment to this idea leads to their understanding of the inconsistency that they see in the work. Wittgenstein is committed at one and the same time, as they see it, to putting forward a metaphysical view and to putting logical obstacles in the way of putting forward metaphysical views. And he is supposed to have had some sort of technique (albeit a 'paradoxical' one) for getting round this. Williams's 'you, too' argument involves taking resolute readers to ascribe a similar inconsistency to Wittgenstein, but (allegedly) failing to recognize that they are doing so. But her argument depends on the idea that resolute readers ascribe to Wittgenstein substantial doctrines about language, from which conclusions about the nonsensicality of certain sentence-constructions can be drawn. This makes of 'nonsense' a quasitechnical term, which is then taken (on Williams's account of resolute readings) to be the crucial term of the Tractatus. Williams thus sees resolute readers as dependent on taking Wittgenstein to have a theory of nonsense. The dependence of the resolute reading on such a theory, though, would merely relocate the inconsistency of the book. Thus, in Williams's summary of her dilemmatic argument, she claims that a theory of meaning must be available if resolute readers are to show that philosophical sentences, which look meaningful, are not; so resolute readers are committed to ascribing to Wittgenstein such a theory, if not by taking some of his sentences to express such a theory then by ascribing to him some ineffable thesis which will do the work of generating conditions of meaningfulness which philosophical sentences fail to meet. We think this involves a failure to see what is involved in the activity of clarification that the author of the Tractatus seeks to practice. What we want to emphasize now is the following: part of what Williams misses here is that this activity does not presuppose any special conception of nonsense: 'nonsense' is not a technical term for the author of the Tractatus.

In the process of philosophical clarification, the use (or lack thereof) that we are making of a sentence (or group of sentences) is meant to become more open to view. This can be done quite informally, as when we ask someone simply whether, by a particular word in a sentence, she means this or that. What is done in that informal way could also be done by inviting her to translate what she wants to say into a notation in which it is no longer possible to put together a sentence understandable in the two (or more) different ways in which her original sentence was. But the attempt at clarification of the thought she is expressing may fail, and, instead of the thought's becoming clear, what the attempt may bring out is that no determinate meaning had been given to some word in the context in which she used it. She may come to see that her own having taken herself to be saying something rested on a kind of illusion of sense. Part of our ordinary capacity to think and speak is our capacity to recognize such things as that 'Jane meringued the eggs' does not use 'meringue' in the way we had already learned; we might, if we have the vocabulary to reflect on this, say that we had previously used it as a word for a kind of stuff, not for an action. If we can take the sentence not to be meaningless, although it uses a familiar 
word in a different way, that's because we cotton on to the new use: it means to make something into the kind of stuff we had called 'meringue' before. If, on the other hand, we are told that 'Jane meringued the equations', we might say that we don't yet understand it, and unless we can guess, or are given, some explanation of the verb 'to meringue' in this sort of context, we might suspect that we had a bit of nonsense. This suspicion rests on no theory of meaning. If 'Jane meringued the equations' is meaningless, it is not because there are some conditions which the sentence violates, conditions which we could get from some theory of meaning. The suspicion of meaninglessness may be unfounded, if the person uttering the sentence can make clear the relevant use of 'meringue'. A 'negative' or 'austere' view of nonsense holds simply that, if there is no such use, the sentence is nonsensical through containing a meaningless word or words (compare Tractatus 5.47321).

Resolute readers hold that Wittgenstein, when he wrote the Tractatus, did not take the procedure of clarification, as he then conceived it, to depend on anything more than the logical capacities that are part of speaking and thinking. Through the use of those capacities, we could, he thought, come to recognize that the sentences of the book itself failed to say anything, and that the very questions that we are initially inclined to take him to be addressing are themselves not questions at all. The activity of clarification did not, as he conceived it, depend on doctrines about the nature of language. The activity of truth-functional analysis was taken by him not to depend on any theory of language put forward in the book; similarly with the use of translation into a 'concept-script' in which logical equivocation was impossible. It is important here to distinguish between taking Wittgenstein to have unwittingly failed to have got free of metaphysical preconceptions (as resolute readers may) and taking him to have intended to put forward a metaphysical view (as standard readers do). ${ }^{34}$ Many of Williams's arguments presuppose that there is no room to draw such a distinction.

We have suggested that what the Tractatus is meant to enable us to do is to use ordinary logical capacities to engage in what one might call the 'interrogation' of philosophical sentences, including the sentences of the book itself. ${ }^{35}$ This is a quite different picture of what is involved in the discovery of nonsensicality from the picture that Williams takes to be at work in the resolute reading. We have tied the 'interrogation' of sentences to the activity of philosophical clarification, an activity meant to bring more fully into view the use of a sentence (in the way in which Russellian analysis can be taken to bring more fully into view the use of sentences containing definite descriptions). The attempt at clarification can bring out that no use has been fixed on for some or other sign, or indeed that we have been in an unclear way trying to run together two quite different sorts of use, wanting neither the one nor the other but both. Clarification is taken to depend upon ordinary logical capacities - capacities that (resolute readers are free to hold) Wittgenstein misconceived in accordance with a picture. Thus, for example, he saw all inference in terms of a picture; he took translation into formal notation to be a far more generally applicable tool than it is. To say that 
Wittgenstein was not, when he wrote the Tractatus, as free of metaphysical preconceptions as he thought he was, or to say that he was in the grip of a picture, is indeed to find the book a flawed work. It matters, though, how we locate the flaws and how we understand them in the context of an understanding of Wittgenstein's aims. Our understanding of where later Wittgenstein saw the flaws to lie can go deeper, we would argue, precisely by taking seriously Wittgenstein's own attempt to take the distinction between saying and showing deeply enough, and not construing the aim of Wittgenstein's own propositions as being that of gesturing at things that can't be said. This, we believe, enables us to take seriously, in a way standard readers do not, Wittgenstein's remark, at §6.54, about throwing away the ladder.

\section{The 'what about showing?' objection}

In the previous paragraph, we speak of 'taking seriously Wittgenstein's own attempt to take the distinction between saying and showing deeply enough'. Here is how we imagine some of our critics, including Williams, responding to our speaking thus: 'What? It is we standard readers who are the ones who want to take the distinction between saying and showing seriously. You resolute readers want to throw it away!' This common reaction to resolute readings is, we think, due to a tendency on the part of commentators on the Tractatus to mistake the bathwater for the baby here: what we want to throw away is only a particular way of understanding the distinction - namely, the sort of understanding of it that figures in standard readings and that we have criticized above. It is itself a noteworthy sign of how deep the attachment to the bathwater goes here, that so many critics of resolute readings (and even some resolute readers themselves) cannot see how there can be any room left for anything properly termed 'a distinction between saying and showing', once the standard sorts of ways of understanding what such a distinction ought to come to are discarded. The only thing in connection with this topic that a resolute reading, as such, would be committed to is the rejection of any account of showing as a revealing of ineffable content. One reason why people who accept a standard reading have generally taken resolute readers to reject altogether the very idea of showing is that they assume that the only possible understanding of it takes it to be a matter of revealing an ineffable content. ${ }^{36}$

Diamond says: 'To grasp that what you were trying to say shows itself in language is to cease to think of it as an inexpressible content: that which you were trying to say. ${ }^{37}$ Conant says: 'The Tractatus shows what it shows (i.e. what it is to make sense) by letting language show itself, through das Klarwenden von Sätzen.'38 These remarks, and others like them in our writings - remarks that involve such unembarrassed invocations of the idea of showing - crop up in contexts in which we seek to indicate that throwing away the ladder need not require throwing away the idea of showing per se, while very much insisting that it does require throwing away the idea of 'showing' to which standard readers wish to 
cling. But, so far, all that this indicates is the following: the features that make a reading 'resolute' (in the sense of that term explained in section 1) do not, as such, require one to give up on every possible way of drawing a distinction between saying and showing. Resolute readers are not obliged to throw away showing while throwing away the idea of 'showing' as part of a Tractatus theory involving our supposed access to a special realm, the denizens of which are supposed to be officially unthinkable, but somehow graspable (in a way that doesn't count officially as thinkable) when 'shown'. All a resolute reading commits one to here is: (1) drawing the distinction in such a way that it applies only to sinnvoll and sinnlose Sätze and never to unsinnig propostional signs; and (2) drawing it in such a way that showing ceases to require an irresolute waffle between wanting to claim that the content of that which is shown cannot be said (because that's what Wittgenstein says) and wanting to hint at what the content in question is (in ways that, in effect, turn it into a kind of quasi-sayable quasicontent). ${ }^{39}$ To fail to draw the distinction deeply enough here means: to construe the 'showing' side of the distinction as a kind of 'conveying' of a quasi-propositional content that we can at least attempt to say (though 'strictly speaking' we are unable to say it). To draw the distinction deeply enough means: no longer being tempted to construe 'showing' on the model of a funny kind of saying. This still leaves it open to different resolute readers to develop different understandings of how showing works. It is important, therefore, to note that other resolute readers may not wish to accept the suggestion we shall now put forward merely to indicate one way in which the notion can be understood. ${ }^{40}$

There are activities, like swimming, about which one might say that the practical mastery of the activity does not have a logical side. Further, unlike the activity of inference, an activity like swimming can be taken in by someone who is unable to engage in it himself. One can imagine a judge of good and bad swimming who himself could not swim. There are other activities, like becoming a physicist, which do have a logical side, but part of the mastery of these activities is the mastery of certain theories; no one who did not know any of these theories herself could judge whether someone had reached, say, a basic level of participation in the activity. Speaking and thinking are different from activities the practical mastery of which has no logical side; and they differ from activities like physics the practical mastery of which involves the mastery of content specific to the activity. On Wittgenstein's view, speaking and thinking do not differ from such activities as physics in that in the former the content that is internal to mastery of the activity is ineffable. That would make the difference too slight. Linguistic mastery does not, as such, depend on even an inexplicit mastery of some sort of content. ${ }^{41}$ Philosophical clarification makes us more aware of the logic of our language, of what is present in (what Goldfarb describes as) 'our understanding of and our operating with the sensical sentences of our language'. ${ }^{42}$ The logical articulation of the activity itself can be brought more clearly into view, without that involving our coming to awareness that anything. When we speak about the activity of philosophical clarification, grammar may impose on us the use of 
'that'-clauses and 'what'-constructions in the descriptions we give of the results of the activity. But, one could say, the final 'throwing away of the ladder' involves the recognition that that grammar of 'what'-ness has been pervasively misleading us, even as we read through the Tractatus. To achieve the relevant sort of increasingly refined awareness of the logic of our language is not to grasp a content of any sort. 'What can be shown cannot be said' (\$4.1212): to take the difference between saying and showing deeply enough is not to give up on showing but to give up on picturing it as a 'what'.

\section{The methodological objection}

Many of Williams's comments are addressed to methodological issues. In particular, she challenges the idea that it is sound methodology to privilege a philosopher's metaphilosophical remarks. She says that this approach 'seems to reverse the proper relation between the content of a philosopher's writings and his remarks on what he takes himself to be doing'. She is there introducing a general maxim which has its force in connection with philosophers the content of whose writings can be fairly straightforwardly taken in. People who accept a resolute reading of the Tractatus do not have any particular tendency to privilege anybody's metaphilosophical remarks, including Wittgenstein's. Even if we were to subtract from the Tractatus remarks such as $\$ 6.54$, and regardless of which and how many such remarks we were to subtract, it is not as if we would be left with a body of statements which our ordinary philosophical techniques of reading can straightforwardly accommodate. (For example, as we will see in section 4, the Tractatus contains remarks about the sorts of propositional contexts in which propositions can occur; the book also has remarks about the relation between sentences with and without quantification. These remarks, taken together, create a problem for the reading of any Tractatus proposition which appears to quantify over propositions; that's to say, they create a problem for the reading of a substantial part of the book.) Since it is fairly obvious, and not disputed by Williams, that the Tractatus, taken as a body of propositions, does not lend itself to straightforward reading, it is not clear what the relevance is supposed to be of a methodological maxim the background for the application of which is the more or less straightforward availability of the philosophical content of a philosopher's non-methodological remarks. Although the standard reading recognizes the existence of problems reading the Tractatus, it underestimates these problems, as we have argued. The importance of Wittgenstein's own methodological remarks has to be decided, not on the basis of general principles about 'privileging' or 'not privileging' this or that, but on the capacity of those remarks to help us, in the particular context of a very puzzling book which forces on us the question how we are meant to read it.

There is a further related point about methodology that it may be useful to clear up. Williams says that Diamond's supposed 'privileging' of Wittgenstein's metaphilosophical remarks makes it a test of a correct reading that it treats 
nonsense in the way that she recommends. Williams says that this may be why Diamond 'admits that she does not know how such an interpretation can be evaluated'. The remark of Diamond's here in question (having to do with the difficulty of evaluation) has nothing to do, however, with 'the' resolute reading as such. ${ }^{43}$ It concerns the activity of imaginative articulation of Wittgenstein's views on ethics. Diamond, in that remark, is discussing the danger of projecting into Wittgenstein's remarks one's own favored ethical views, and her remark is specifically concerned with the difficulty of judging whether one has succeeded in avoiding that danger. It has nothing to do with the idea that one should privilege Wittgenstein's metaphilosophical remarks, and then, based on these remarks, make some independently ascribable thesis about nonsense a condition of reading the Tractatus rightly.

We have, in our writings, stressed the importance of our being able, as readers, to distinguish certain remarks (such as the Preface and the concluding sections) that serve to 'frame' the work as a whole (and hence the activity of clarification practiced by the author in the work) from the remarks in the 'body' of the work that serve to exemplify that activity (and hence furnish the reader with a ladder that she is meant to climb and, eventually, throw away). But such a distinction does not commit us to 'privileging' the remarks that can be read as framing the activity practiced within the body of the work. The viability of such a construal of any particular remark (as furnishing a frame through which to view the activity practiced in the course of the bulk of the work) depends upon the viability of the reading of the rest of the book that such a construal helps to make possible, and vice versa. Conant has been explicit about the methodological issues here. He notes that, at $\S 6.54$, we are told that the sentences of the work have succeeded as elucidations when we recognize them as Unsinn. But, he argues, we cannot understand what $\$ 6.54$ asks us to do, independently of an appreciation of the structure and method of the work as a whole, through which alone we can come to some understanding of what Wittgenstein meant by 'elucidation' and of how he was deploying the term 'nonsense' in the book. ${ }^{44}$ Conant explicitly rejects the idea that we should work with a two-part methodological maxim, to the effect that first, we ought to try to get a fix on the central metaphilosophical doctrine of the book (by basing it, say, on an independently ascertainable interpretation of what $\$ 6.54$ says about how we should read the book), and then, second, we ought to try to interpret the rest of the book in the light of that fixed point, ignoring anything that gets in the way of such a reading. On the contrary, his point is that we cannot get a handle on what a remark such as $\$ 6.54$ says apart from a detailed understanding of much that happens along the way in the book (such as an understanding of what the book seeks to show us along the way about nonsense and the exemplifications of the practice of elucidation it thereby affords). We must interpret a remark such as $\$ 6.54$ in the light of what we find in the body of the book; and vice versa. These two forms of understanding must come with each other or not at all. There is no forced choice here of the sort that Williams suggests. There is no forced choice between fixing 
upon an antecedent interpretation of Wittgenstein's more general hints and instructions to the reader (and then working out to a reading of the rest of the book only once such an interpretation is in place) and ignoring Wittgenstein's more general remarks about how the work is to be read (and concentrating instead on the rest of the book to the exclusion of such remarks). Rather they the remarks about the book and the book that they are about - must be interpreted in the light of each other.

\section{Reply to Peter Sullivan}

Sullivan has written a number of interesting articles on the Tractatus that we regrettably cannot afford to discuss on this occasion. Our comments here will be mostly restricted to replying to his essay 'What is the Tractatus About?' But, before turning to this task, we would like to make one general remark about his larger body of work on these issues: we find Sullivan to be the most perceptive and helpful critic of resolute readings to have come along thus far. His criticisms of such readings avoid many of the most common misunderstandings of them and thereby open up the possibility of a constructive continuing conversation between those who view such readings with sympathy and those who view them with suspicion. In his other writings (that we mostly do not address below) some of Sullivan's more local remarks - for example, about particular moments in the writings of one or another resolute reader - are very astute. He identifies revealing moments in which resolute readers fail to agree among themselves (and in which a given reader fails to remain in agreement with him- or herself, sometimes over a series of articles and sometimes within a single article). ${ }^{45}$ Taken together, these remarks point up possible tensions and significant differences in the ways in which resolute readings can be and have been developed. They also bear witness to a serious attempt on Sullivan's part to come to terms with such readings and to see what they can and cannot accomplish. Moreover, one senses that, whatever their differences, Sullivan shares with many resolute readers a genuine fascination with and affection for the Tractatus: he, too, wants to give the book the best run for its money; and he is not at all inclined to ascribe a high degree of tolerance for inconsistency or 'paradox' to its author.

Many of the issues here are complex and elusive, so the conversation will be, no doubt, a long one. Our remarks here are intended merely to take up Sullivan's invitation to such a conversation and hopefully move it forward another step or two. One reason, no doubt, dialogue seems more readily possible here is that Sullivan's interpretative starting point is not quite as far removed from that of a resolute reading as is usually the case among critics of such a reading. He appears, for example, to share with resolute readers the sense that there is much in the Tractatus that Wittgenstein commentary has yet to understand, and that acquiring the resources for such an understanding will require going beyond the standard sort of reading. There is also important agreement on some very crucial points of detail. Thus, for example, Sullivan's attitude 
towards resolute readings is very different from Williams's. While Williams is almost exclusively concerned to criticize 'the core commitments' of a resolute reading, Sullivan takes these to be 'clearly correct'. ${ }^{46}$ Many of Sullivan's reservations about what resolute readers have claimed on behalf of their readings are connected to a skepticism about how much of the Tractatus one can really come to understand merely by coming to see that the author of that work is indeed committed to a project that is properly characterized by the core commitments of such readings. ${ }^{47}$ Therefore, whereas Williams primarily faults resolute readings for their glaring commissions (their positive misreadings of the book), Sullivan primarily faults them for their glaring omissions (their failure to deliver anything that really deserves to be called a reading of the book). ${ }^{48}$

We suspect that there may be some misunderstanding here. In particular, we suspect that some of what Sullivan takes us to want (and to have failed) to deliver may turn on a misunderstanding concerning how much we take our criticisms of standard readings to deliver, without supplementation, in the way of a complete reading of the Tractatus. ${ }^{49}$ But this is not to deny that some part of Sullivan's sense of the gross insufficiency of resolute readings (his sense that essential elements of a proper reading of the Tractatus simply go missing on such readings) is due not just to what resolute readers do not say but also to some of the things that they do say - and hence to genuine disagreements about how much the author of the Tractatus himself intended to deliver. It will, no doubt, probably take some time to unravel where our differences really lie here - i.e. where our apparent differences are due merely to the first sort of gap (between how much Sullivan thinks we think resolution alone can deliver in the way of a detailed reading of the text and how much we think resolution, without supplementation, can deliver) and where our differences are really due to the second sort of gap (between how much he thinks the author of the Tractatus has to deliver in order to be able to carry out his program of philosophical critique and how much we think he has to deliver in order to be able to do this). We do not, in our remarks below, take the time to sort out misunderstandings that may be due to the first sort of gap. ${ }^{50}$ We focus, instead, on the second gap - on where (at least some of) the real disagreement between us lies - in the hope that, as the conversation proceeds, the first gap will gradually close of its own accord.

No one, we think, could disagree with Sullivan's initial remark (in 'What is the Tractatus About?') that the Tractatus is in many ways a perplexing and obscure book. The question he raises is what the book is about; and he hopes to be able to provide a significant part of the answer. A key to the reading of the book is, he suggests, the identification of a philosophical vision, a vision of the relation between thought and world, with which the book is centrally concerned. The vision is that of transcendental idealism, and a main aim of the Tractatus, on Sullivan's view, is to make plain to readers the kind of double-think involved in attempting to hold on to such a vision, and indeed the kind of double-think involved in attempting to hold on to it while maintaining that it cannot be put into words, but shows itself. 
How does Sullivan get there? He begins with what is intended to be an uncontroversial account of 'the philosophical system of the world, and thought about the world', presented by the Tractatus. Part of this intentionally uncontroversial account is a story about how, in the light of the ideas in the book, we might think about the proposition that $\mathrm{P}$ entails $\mathrm{Q}{ }^{51}$ And what we are supposed to see in the case of the proposition about $\mathrm{P}$ and $\mathrm{Q}$ is meant to illustrate the lesson we are taught by the Tractatus about philosophical discourse more generally. So, part of Sullivan's intentionally uncontroversial account of the Tractatus is this: the system of the Tractatus is meant to reveal how discourse motivated by characteristically philosophical ambitions involves a kind of double-thinking and lapses into nonsense. The question for him then becomes how one gets from that lesson to some deeper understanding of the philosophical aims of the Tractatus.

In the middle of his essay, Sullivan discusses very briefly a different kind of approach to the Tractatus, which rejects the idea that some grasp of the Tractatus system will put us into a position to see what is the matter with philosophical discourse in general. So the idea (included in the supposedly uncontroversial account of the Tractatus) that the system provides a general lesson about doublethinking and nonsensicality, applicable to any bit of philosophical discourse, is not, Sullivan seems here to be suggesting, entirely uncontroversial. He provides, as an example of the quite different approach, a summary of Warren Goldfarb's view. Goldfarb argues that, if we attempt to work through Tractatus ideas, like the idea of possibility that figures in $\$ \$ 2.0122-3$, we shall find that these notions fall apart on us. ${ }^{52}$ Goldfarb reads Wittgenstein as having intended us to recognize that his propositions collapse; he meant us to try to follow through on what they seem to mean, and thereby to find that they mean nothing. This would be a 'piecemeal' understanding of how the book undermines its own propositions.

At this stage, we want to leave the question open whether one should see the Tractatus as providing a general lesson applicable to all philosophical discourse or a piecemeal approach to philosophical propositions. We turn back to Sullivan's initial summary of how the book is supposed to work. Because he intends his account to be uncontroversial, he omits textual references. The first part of his account concerns objects, facts, thoughts, and propositions, as they are discussed in the Tractatus; and, indeed, for everything Sullivan says about these matters, textual references could be provided. But what is striking is that, when he goes on to explain how 'the system', as he has thus far explained it, applies to 'P entails Q' (the case which is supposed to exemplify for us the application of the system to philosophical discourse), there is no longer the kind of obvious and close connection with textual passages which was available for the first part of his exposition. This is important, we think, because one's whole approach to the Tractatus will be shaped by one's answer to the question whether 'the system' enables us to see, in a fairly direct way, that there is a kind of double-think inherent in philosophical discourse. ${ }^{53}$ And this is much more controversial, we think, than Sullivan recognizes. 
Let us look harder at 'P entails Q', and Sullivan's account of how the Tractatus-system enables us to raise questions about that proposition, since so much is made to depend on that. The account starts with this point: that $P$ entails $Q$ is not the obtaining of an elementary fact nor something the truth of which consists in the obtaining of a certain selection of elementary facts. That $P$ entails $Q$ appears not to be a reporting of something that is the case, in the way in which the system of the Tractatus has enabled us to grasp what it is to report something. Sullivan is here suggesting that the 'system' provides a general method of identifying propositions that are at any rate problematic in that they appear to be reports but do not appear to state the obtaining of an elementary fact or of any selection of such facts. ${ }^{54}$ We want to get to a better way of thinking about 'P entails $\mathrm{Q}$ ' in the hope that the example will help us to reach greater clarity about the Tractatus and its aims. Our attempt to do so will come in three steps. We shall turn to the task of trying to get clearer about 'P entails Q' after two preliminary points.

1 The attempt to apply the Tractatus-system to the proposition that $\mathrm{P}$ entails $\mathrm{Q}$ takes us to have a grasp, at least some grasp, of what that proposition says to be so or attempts to say to be so. Sullivan has argued elsewhere that one cannot simply infer from some general principle about nonsense that we cannot see what a genuinely nonsensical proposition attempts to say to be so. ${ }^{55}$ But no such inference need be involved, though we do indeed think that Sullivan's discussion of attempts to do what is impossible is not relevant to the question whether remarks of the general sort 'The proposition ... is an attempt to say something which there is no such thing as the saying of' are nonsensical. To raise doubts about Sullivan's claims concerning what ' $\mathrm{P}$ entails Q' attempts to do, one doesn't need a general principle about impossible attempts, but rather a general suspicion about philosophers: when a philosopher discussing the Tractatus claims to discern what some proposition or would-be proposition is attempting to say, that philosopher may be discovered not to have carried out any attempt at clarification of the proposition or would-be proposition in question.

2 Suppose, instead of considering what the implications are of the system of the Tractatus for 'P entails Q', we first consider instead Tractatus §5.54: 'In the general propositional form, propositions occur in other propositions only as bases of truth-operations.' At first it may seem as if Tractatus $\$ 5.54$ gives us a direct method of criticizing 'P entails $Q$ '. 'P' and ' $Q$ ' are intended to be markers of the occurrence of propositions; but 'entails' is plainly not a truth-functional connective. So it looks as if $\$ 5.54$ suggests that ' $P$ ' and 'Q', as they occur in ' $\mathrm{P}$ entails $\mathrm{Q}$ ', are not being used as propositional signs. Since no other use has been assigned to them, the whole, 'P entails Q', is nonsensical. That argument is inadequate, as the Tractatus indicates. For, immediately after $\$ 5.54$, Wittgenstein tells us, in $\$ 5.541$, that a proposition may merely appear to be one in which propositions occur non-truth-function- 
ally. What needs to be done in such a case is that the appearance of nontruth-functional occurrence has to be investigated. We need to attempt to clarify the proposition which appears to be one in which propositions occur non-truth-functionally. The moral of the story so far is two-fold: first, we may easily reach a point in our dealing with a proposition at which it may seem as if the proposition in question says that something is so and yet also appears not to 'fit' some part of what we take to be the Tractatus's official view of propositions; and, second, we should not be too hasty in drawing any conclusions at this point in our investigation. What happens in $\S 5.541$ is that we are given a kick. What being kicked does is indicate that we need to try to clarify the particular proposition in question, not apply to it as it stands some bit of the Tractatus's doctrine or system.

We now turn to the task of trying to get clearer about 'P entails Q'. The Tractatus says that philosophy is an activity of clarification. What would it be to clarify, or to attempt to clarify, 'P entails $Q$ '? What we shall sketch is one possible approach, drawing on some work of Michael Kremer's. ${ }^{56}$ It will be helpful to consider a more specific version of Sullivan's example: suppose that we want to say of the proposition formed by conjoining two propositions $\mathrm{p}$ and $\mathrm{q}$ that it entails p. To clarify '(p . q) entails p', we might begin by re-writing it: '[(p . q) $\supset$ p] is a tautology'. We need to ask (following Wittgenstein's suggestion at §6.211) what the use might be of a proposition like ' $[(p . q) \supset p]$ is a tautology'. Here we should note that the $6.1 \mathrm{~s}$, the $6.2 \mathrm{~s}$ and the $6.3 \mathrm{~s}$ all contain discussion of the use of different groups of propositions which are not senseful propositions: tautologies, equations, and principles of mechanics. ${ }^{57}$ Wittgenstein is engaged in clarification of the use of these propositions; we take this to indicate that clarification, as Wittgenstein understands it, is not limited to senseful propositions. Wittgenstein says (at \$6.1221) that, although we can see from two propositions themselves that one follows from the other, we can also see that the one follows from the other by combining them with one as antecedent and the other as consequent of ' $\supset$ ' and calculating that the combination is a tautology. Calculating that the combination is a tautology can then be useful in enabling us to recognize what can be inferred from what, though we could indeed grasp what can be inferred from the propositions themselves. The justification of the inference will lie in the propositions themselves, but this may not be immediately evident, and keeping a record of the calculation that shows what can be inferred from what may thus be useful. Keeping such a record of our logical calculations is analogous to keeping a record of arithmetical calculations. Arithmetical calculations have their use in that they guide us in passing from one ordinary (non-mathematical) proposition to another (\$6.211). Michael Kremer suggests that we understand the use of mathematical equations as records of calculations. If we are able to pass from one non-mathematical proposition to another, the justification lies in the two propositions themselves, but a calculation can make this plain to us; and keeping a record of the calculation, in the form of an equa- 
tion, can serve as a kind of short-cut (as Kremer puts it) for use in future passings from one non-mathematical proposition to another. If we want to keep a record of the calculation through which we recognize that '(p . q) つp' is a tautology, there are various ways in which we might do this. We might write ' $[(p . q) \supset p]=$ TTTT(p,q)', using two bits of Tractatus terminology. The equal sign there comes from $\S 4.241$ (cf. also $§ 6.23$ ), where Wittgenstein says that the equal sign indicates that the two expressions on either side can be substituted for each other; and 'TTTT(p,q)' uses the notation described at $\$ 4.442$; it is a sign for the same proposition as ' $(p . q) \supset p$ ', but written in such a way as to make it perspicuous that it is a tautology. The use of ' $[(\mathrm{p} . \mathrm{q}) \supset \mathrm{p}]=$ TTTT $(\mathrm{p}, \mathrm{q})$ ' would simply be as a record of the calculation that shows that ' $(\mathrm{p} . \mathrm{q}) \supset \mathrm{p}$ ' is a tautology. The equation marks the point of view from which we consider the expressions on either side (§6.2323): they are substitutable. The equation in which we mark their substitutability records the calculation through which we recognized the tautological character of the original expression; the equation thus can serve as a record that can be used in guiding future inferences. Our suggestion is that ' $\ldots$ is a tautology' and '.. = taut' should be understood as generalizing (for any number of arguments) the approach that we have suggested for the case in which the tautology that records a calculation involves two truth-arguments. The use of such propositions is essentially as records of calculations that such-and-such propositions, so combined, yield a tautology. (In other words, we are suggesting that 'taut' in '= taut' is a propositional sign that could also be written out, in any actual case, as 'TTTT ... T(p,q,r ...)'58 and that ' - is a tautology' be understood as a way of writing ' $\ldots=$ = taut'.) That the propositions in question, thus combined, do yield a tautology is recognizable from the propositions themselves, but records of such calculations have a use in making it unnecessary for us to recalculate, and thereby giving us a short-cut to be used in inferences from one or more non-logical propositions to a non-logical proposition. We would further suggest that 'P entails $Q$ ' can have the same function as 'P $\supset \mathrm{Q}$ is a tautology'. The equal sign which occurs between propositions in our account has a function not far from the function of putting alongside each other 'On kutsut' and 'There's a party' in Finnish for Travelers. When Wittgenstein wrote that propositions occur in other propositions only as truth-arguments, he was speaking of the general propositional form, in which propositions are used to say that something or other is the case. A proposition with an equal sign in it does not do that; it is a 'pseudoproposition' (see $\$ \S 6.21-6.211$ ). But this does not mean that such propositions are nonsensical; they have a use, just as does the production of a pair of sentences alongside each other in Finnish for Travelers. (Writing ' $\mathrm{p} \supset \mathrm{q}$ is a tautology' as 'p $\supset \mathrm{q}=$ taut' is useful in that the latter bears on its face, in the presence of the equal sign, that it is a 'pseudo-proposition', and that we need to pay attention to its use to understand how it is different from nonsensical pseudo-propositions.) Similarly, 'P entails Q' has a use and is not nonsensical, though it equally is not the expression of a thought that anything is the case. ${ }^{59}$ We should not, that is, read it as if it were clear that it was trying to express some 
kind of relation between $\mathrm{P}$ and $\mathrm{Q}$. If someone did not want to use it in the way we have described, nor in any other way, one might then indeed infer that she was speaking nonsense. But such a charge of speaking nonsense would then apply only to what she was attempting to do with the propositional sign, not to some flaw resident in the propositional symbol that we can see in the sign when it is put to the sort of use we have attempted to characterize above (see §3.326). We may seem to be a long way from Sullivan's question: 'What is the Tractatus about?' But, just as his argument moved from his story about how the Tractatus is supposed to teach us something about 'P entails Q' to a story about what the book is about, we hope that our alternative story about how the Tractatus teaches us something about 'P entails Q' will help us to respond to Sullivan's question about the book as a whole and what it is about. To that we now turn.

We mentioned that, after Wittgenstein says that propositions occur in other propositions only truth-functionally, what he does is attempt to clarify certain propositions that at first appear to contain non-truth-functional occurrences of other propositions. The clarification (of the kinds of proposition with which he is concerned there) will make more perspicuous the kind of use they have. One thing that we can gather from Wittgenstein's handling of those propositions is that it will not in general be immediately obvious whether a proposition constitutes some kind of counter-example to something that we take the Tractatus to say. It is therefore quite unclear how we are going to be able in general to cotton on to some proposition's being an expression of some kind of double-thinking. A particular proposition may have some use that is not immediately obvious, and the various procedures of philosophical clarification are meant to come into play in helping us to discover what the use might be of some proposition about which we might take ourselves to have suspicions. As came out in our treatment above of Sullivan's own example, a proposition may appear to be eminently eligible for Tractatus-style unmasking as a bit of double-think, but may then turn out not to be so after all. There are three separate points that are all worth making here:

1 It is central to the teaching of the Tractatus that there is no straightforward way to read off a propositional sign whether or not it is in accord with the system of the Tractatus. We cannot just take ourselves to be able to 'spot' the ambition with which a stretch of discourse has been uttered, and thereby to be in a position to unmask the stretch of discourse as involving characteristically philosophical double-think. Sullivan takes himself to be able to read precisely such an 'ambition' off the innocuous 'P entails Q'. (We will return below to the topic of the philosopher as would-be 'spotter' of philosophical illusions.) One thing the Tractatus is about is how we are vulnerable to philosophical illusion in the course of trying to satisfy our ambitions as illusion-spotters. Perhaps better put: the Tractatus is 'about' the activity of philosophy as clarification; and part of its being about clarification is its enabling us to recognize that, and how, we ourselves may fail to see a need to clarify what we wish to say especially when we seek to take up the office of the critic of philosophy. 
2 More particularly, the Tractatus holds that we cannot take ourselves to be able to 'spot' nonsensicality in a proposition simply by noticing that a word or words in it is not used in the way in which it is normally used and that, as far as we can see, it has been given no other use. We cannot tell, merely from the fact that some word or words is not given the use that it normally has (or that its surface grammar suggests that it ought to have) that it has been given no other use. The idea that a nonsensical would-be proposition is nonsensical only through containing some word or words to which no meaning has been given does not provide any kind of principle for the immediate identification of some sentence or stretch of discourse as nonsensical.

3 A readiness to identify a stretch of philosophical discourse as nonsensical may come from a sense that we know what it is trying to say, and that we can identify the stretch of discourse as nonsense through identifying that aim. But if we identify a stretch of discourse as nonsensical, we cannot be claiming to understand it. And if there is a stretch of discourse produced by someone, a stretch that we do not understand, we are not in general licensed merely on that ground alone (this should be obvious enough from ordinary non-philosophical discourse) to conclude that the stretch of discourse is nonsensical. As a general point, few would contest this. But many readers of Wittgenstein unwittingly fall into the trap of taking themselves to be able to declare that something is nonsense simply on the grounds that the words are being used in a way that differs from how they would ordinarily expect those words to be used. ${ }^{60}$ Wittgenstein, in his later philosophy, in which he does not write with the concision of the Tractatus, makes plain that the sentences that are used in philosophy frequently have perfectly senseful uses. 'When would we say this?' he frequently asks. 'I am the only one who feels real pain' is an example he subjects to this sort of investigation in the Blue Book. If claims made by a solipsist are nonsensical, that can be shown only through the solipsist's rejecting possible ways of using the sentences in question, and coming to see that he has no alternative use in mind, and not because there are no possible uses of the sentences in question. Neither in his later philosophy nor in the earlier philosophy is there some quickie principle that will enable us to identify a stretch of discourse as nonsensical; there is nothing that can enable us to pass such a verdict on a stretch of discourse apart from an engagement in a process of clarification in which an interlocutor comes to see for herself that no available use of a sentence will satisfy the 'ambition' that draws her to the form of words in question.

In case it is not apparent, it should be noted that our discussion so far has been guided in part by a reading of Tractatus $\$ 6.53$. It is therefore perhaps worth noting that Sullivan, in an earlier essay, writes that $\$ 6.53$ is not one of Wittgenstein's better remarks. ${ }^{61}$ He thinks that, so far as it provides a conception of how the philosopher ought to proceed, we ought to drop that conception. The criticisms that he makes of $\$ 6.53$ depend on a particular reading of that passage. According 
to his reading, to follow out the suggestion of $\$ 6.53$ would be to seize on any sentence which a philosopher comes out with and to demonstrate to the philosopher by an immediate application of a general principle about nonsense (that a sentence is nonsensical if it contains a sign or signs to which no meaning has been given) that what the philosopher has said is nonsensical. Sullivan objects that this would be a procedure that resembled the pernicketiness of ordinary-language philosophers, some of whom attacked anyone who took a word and used it in a philosophical context in some way different from its ordinary use. ${ }^{62}$ A further criticism that Sullivan makes is that an approach of the sort recommended at $\S 6.53$ (the immediate-pounce approach, as he sees it) would never allow the philosopher in question fully to develop the view she was attempting to put forward to the point at which a genuinely telling criticism could be put forward. The $\S 6.53$ approach would just snap into action after the first sentence uttered by the philosopher containing a word apparently with no meaning, and the line of thought to which the philosopher was attracted would never genuinely be confronted. ${ }^{63}$ But we think that Sullivan's reading of $\$ 6.53$ misses what is involved in demonstrating to another person that she has given no meaning to some word or other that she has used. This certainly cannot be demonstrated in the 'pernickety' way that Sullivan reads into $\$ 6.53$. The pernickety Wittgensteinian critic who follows 'the strictly correct method' of $\$ 6.53$ as Sullivan construes it says to the would-be metaphysician: 'Here and here and here in what you have said there are words which have been given a use in their occurrence in such-andsuch contexts, and you are not using them in those contexts. So: you are talking nonsense!' That 'pernickety' method would indeed be dissatisfying to the person on whom you tried to use it; but it is in any case no demonstration that the person has come out with nonsense. For the pernickety method makes no attempt at all to clarify what the person has tried to say, or to invite the person to participate in such attempted clarifications. The pernickety method provides no demonstration of nonsensicality; what would genuinely be a demonstration isn't in view in Sullivan's remarks at all: namely, the attempted clarification of the person's claims, the attempt leading to a recognition by the person that there is nothing meant by some sign or signs in what she has said, nothing which she wants to use that sign or those signs to mean. This kind of demonstration involves patience and a willingness to try to understand what the person who comes out with the apparently metaphysical remarks might be trying to express. ${ }^{64}$ In light of the delicacy with which Wittgenstein characterizes the task of clarification elsewhere in the Tractatus, and given the difficulties that he evidently thinks attend such a task, we find Sullivan's reading of $\$ 6.53$ (and, in particular, his reading of the pernickety method into that remark) to be uncharacteristically uncharitable on his part and to obstruct his view of how that remark is meant to shed light on the conception of clarification that the Tractatus itself aims to practice. ${ }^{65}$

The kind of attempt to clarify what someone has said, which can reveal to her, in its failure, that she had nothing really in mind, does not have to rely on identifying her philosophical ambitions as ambitions that show a wrong kind of 
perspective. It does not have to rely on ascribing to her a desire to take up a perspective on language, or anything of the kind. ${ }^{66}$ It can proceed through offering possible paraphrases, and through inviting paraphrases. It may use what it claims to be translations of some of what is said into some supposedly more revealing linguistic form, as in the case of Russell's theory of descriptions, and in the case of the paraphrase we offered above of 'P entails Q'. It may involve attempts to follow through on inferential patterns involving the proposition. Attempting clarification, and allowing such attempts to reveal, in their failure, that nothing was meant by some stretch of discourse, can demonstrate to a person that she had meant nothing. Why, though, should such a method be regarded as the only correct one? To answer this question, we need to notice a surprisingly frequently ignored feature of the philosophical situation, but a feature that Wittgenstein has in view in placing $\$ 6.53$ together with $\$ 6.54$. When we think about the application of the Tractatus to philosophical confusions, we frequently think of ourselves as addressing someone whom we believe to be in such a state of philosophical confusion, a would-be metaphysician. We think of ourselves as trying to derive from the Tractatus an approach that will make clear to that person that she is engaged in double-thinking, in thumb-catching, or something of the kind. The feature of the situation that we thereby ignore is that we ourselves, the would-be enlighteners of the metaphysician, may be equally deeply enmeshed in philosophical difficulty or confusion. In the scenario, we ourselves are invisible. We grasp what is at bottom wrong with the view of the other; the question for us, we think, is how we are to make the illusion from which the other person suffers available to her. What we see, or think we see, to be at bottom wrong with the view of the other is not the failure of her words to say anything, but the philosophical thoughts to which she is driven, the kind of way in which she thinks she can think philosophically about the world and thought. We see her, not our own thought about her, nor how far, in that thought about her, we remain ourselves in the grip of undiagnosed illusion. We see her thought as what the Tractatus shows to be no thought at all. We don't see what that shows about us.

'Resolution', as we said in our opening remarks to this part of the paper, does not itself furnish a 'reading' of the Tractatus; nor, as we said in our opening remarks in section 1, do 'resolute readers' have on offer some kind of key to a reading. Wittgenstein is certainly concerned in the Tractatus with various forms of philosophical confusion, including the transcendental idealism that Sullivan puts in the center of his attempt to explain what the book is about. What convinced Wittgenstein of the significance of his achievement in the book was (among other things) that it provided a critical approach that would be applicable to many different philosophical views, including views as far from each other as those of Schopenhauer, Russell and Frege. But how in detail it is to be applied to this or that particular view of Schopenhauer's, or Frege's, or Russell's, still has to be carefully worked out. 'Resolution' says nothing about how to do this, only how not to. To pick up a phrase from Sullivan (which we use in a somewhat different way from Sullivan), resolution is a kind of constraint on a reading, rather than a reading. ${ }^{67}$ 
Conant describes (in the closing pages of 'The Method of the Tractatus') what happens if the Tractatus is successful in its aim with a particular reader: its success lies in that reader's recognizing that the philosophical sentences of the work are nonsense. But it very much matters here that included within this recognition is the recognition that many of the sentences that we ourselves may be initially inclined to come up with, in explaining how the book dispels philosophical illusions, will themselves also turn out to be nonsensical. If the book is successful with us, we give up the idea of our enlightened perspective on the thought of would-be metaphysicians, realists, transcendental idealists, and solipsists. We see our perspective of enlightenment about what they are attempting as itself illusory. This doesn't mean that we have no way to engage with them; it doesn't mean we have no way to read the book. But adhering to an 'austere' conception of nonsense is not itself going to be a guide to the book, or a guide to what to say to would-be metaphysicians. In particular, it does not tell us how far, and in what way, we may in some particular case be able usefully to employ forms of expression that we might recognize as nonsensical. But the allowance is not a matter of the providing of general principles, or a 'system', from which nonsensicality can be inferred. The importance of $\$ 6.53$, and its placement immediately before $\$ 6.54$, is that it pushes us to recognize what is involved in our own use of expressions that are themselves nonsensical. We need to recognize how easy it is to wish to 'demonstrate' nonsensicality through appeal to nonsense, or to quantifications that apparently 'go over' nonsense, as in talk of someone attempting to say 'something' that cannot be said, as if using quantifiers enabled one to pick out a range of nonsensical would-be sayings or thinkings, without one having oneself actually to engage in the production of nonsense.

In summary, then, of our reply to Sullivan, we can say that our disagreement with him goes back behind his initial way of setting out possible sorts of responses to the recognition that the philosophical system of the Tractatus appears to be vulnerable to the criticisms of philosophy that we can see to follow from the system itself. A 'resolute' reading is not, on our view, one sort of response to such a recognition. For we reject the explanation Sullivan gives of how 'the system' gives rise to criticisms of philosophical discourse. The critical standpoint on such discourse depends, as Sullivan sees it, on applying to philosophical discourse a characterization of senseful discourse from which it immediately follows that philosophical discourse, including that in which the Tractatus system is supposedly put forward, is problematic. On our reading, if many of the propositions in the Tractatus are vulnerable to a form of criticism that reveals them to be nonsensical, this can't be deduced from 'the system' of the book, but has to be established by looking at the propositions themselves and subjecting them to the kind of critical examination we have described, which involves coming to see how attempts to make clearer what they say collapse. There may be generalizations that we are drawn to make about how such investigations proceed and what to look out for, but no such generalization provides a principle by which the propositions of the Tractatus (or any other sequence of 
propositional signs) can simply be inferred to be nonsensical. ${ }^{68}$ 'Austerity' is certainly not such a principle, nor have we ever meant to suggest that it is. Indeed, we do not wish to suggest anything as a 'key' to reading the book (i.e. as a 'guide' of the sort that Sullivan thinks must be required and that he imagines resolute readers must think austerity provides), but we do think highlighting the character of Wittgenstein's conception of philosophy as an activity of clarification is something that can help one to make progress in reading this deeply obscure and difficult, but also immensely stimulating and rewarding work.

\section{Continuities and discontinuities in Wittgenstein's thought}

As we have already indicated above, a resolute reader of the book need not be committed to the idea that Wittgenstein's own conception of what he was doing in the Tractatus was accurate or otherwise unproblematic. Resolute readers may ascribe to Wittgenstein misconceptions - misconceptions that they take to have been embodied in his ideas about the activity of philosophical clarification. A resolute reader may hold that, when Wittgenstein wrote the Tractatus, his conception of philosophical clarification reflected his being in the grip of a picture of language, although he did not then realize it. Such a reader may hold, for example, that Wittgenstein's having taken himself to have dissolved the 'big question' of the nature of language (and thus to have solved the problems of philosophy 'in essentials' by having demonstrated a method through which all confusions could be clarified) itself reflected a kind of philosophical confusion which colored also his ideas about philosophical method. The question that divides resolute readers from non-resolute readers is not: are there no important differences between early and later Wittgenstein? Or: was later Wittgenstein mistaken in regarding the author of the Tractatus to have been committed to problematic metaphysical theses? The question that divides them is: did the author of the Tractatus understand himself (rightly or wrongly) to have found a way to do philosophy that eschews any commitment to a metaphysical thesis? ${ }^{69}$

Williams identifies, as one consequence of a resolute reading, the rejection of one sort of account of how Wittgenstein's thought changed. A resolute reading will reject the idea that he changed his views by giving up, in his later thought, a theory of meaning that he had put forward in the Tractatus, and that he thought could be used 'to end philosophy by solving its legitimate problems and dissolving the rest'. If, as resolute readings have it, he did not put forward a theory of meaning in the Tractatus, that account of the change in his thought must be rejected. But it certainly does not follow that a resolute reading commits one to holding that Wittgenstein did not change his views about the aim of his philosophizing or about its method, or about what was involved in liberating us from philosophical confusions or illusions. If one says that the resolute reading commits its holder to saying that Wittgenstein's aim in his earlier philosophy was therapeutic, and that his aim in his later philosophy was therapeutic, that alone 
would not show that there is no deep and significant change in his aim. The word 'therapy' says very little (as Williams herself explicitly recognizes). Nor does the absence of significant change follow from anything else that Conant or Diamond or most other resolute readers have said. Diamond in fact discusses important differences between Wittgenstein's earlier and later philosophy in the two introductory essays of The Realistic Spirit. ${ }^{70}$ (We will quote something she says there in a moment.) Conant and others who accept some sort of resolute reading have also discussed the deep changes in Wittgenstein's thought. ${ }^{71}$ The important issue here is not how they have done it, but that a resolute reading is committed to rejecting only those accounts of the change in Wittgenstein's thought that depend on not reading the Tractatus in a resolute way, and is not committed to any 'strong' thesis of continuity. If one assumes that the only way to account for the profound changes in Wittgenstein's thought is in terms of his having put forward a metaphysical theory or a theory of meaning or both in his earlier thought, and his having given up the theory or theories later, then one will take resolute readings to be committed to 'strong continuity'; but the idea that that is the only way to understand the profound changes in Wittgenstein's thought should in any case be rejected. Not only are resolute readers, as such, not precluded from taking there to be profound discontinuities between Wittgenstein's early and later thought, but, on the contrary, if later Wittgenstein viewed his early work as an exemplary illustration of how, in philosophy, one can take oneself to have resolutely eschewed all metaphysical commitments while still remaining knee-deep in them, then a resolute reading may help us to attain a better understanding of why later Wittgenstein took his early work to be the expression of the metaphysical spirit in philosophy par excellence.

Williams says that Diamond maintains that a correct understanding of Wittgenstein's intentions will enable us to see that he 'never fundamentally changes his views nor alters his methods'. Williams gives no citation for this statement. In 'Throwing Away the Ladder', Diamond does, as Williams notes, write about Wittgenstein's continuing desire to free us of the illusion we may have of needing a kind of external perspective on thought or language. ${ }^{72}$ But neither $^{2}$ there nor anywhere else in any of our writings does either of us ever say that Wittgenstein never changed his views nor altered his methods. We have, however, both written many things that say the contrary. The following is an example of something one of us has written, ${ }^{73}$ and of the sort of thing that we take reading the Tractatus in the manner we recommend to put one in a position to be able to say, about the relation between Wittgenstein's early and later philosophy:

$[\mathrm{T}]$ here is a sense in which the Tractatus might be described as metaphysical, even though it is not concerned with features of reality underlying sense, with things that are the case although they cannot intelligibly be said or thought to be the case. It is metaphysical ... in holding that the logical relations of our thoughts to each other can be shown, completely shown, in an analysis of our propositions. It is meta- 
physical in holding that it is possible for propositions to be rewritten in such a way that the logical relations are all clearly visible, and that, by rewriting them in that way, what propositions our propositions are, what combinations of signs, would also be clear, as would be what all propositions have in common. This is not a view about what there is, external to language or thought, but about what they essentially are (despite appearances), and about what we can do, what it must be possible to do. The belief that there must be a certain kind of logical order in our language (the belief reflected in our seeing that order as already there, given the understanding we have of the signs we use (Philosophical Investigations, I, $\S \S 101-2))$ : this is a belief also in what we must be able to do, given that we understand sentences and use them, where using them is saying things in determinate logical relations to each other; and these relations are what (totally laid out) shows us what sentences we use, as Russell's analysis of sentences containing definite descriptions showed us in part.

What is metaphysical there is not the content of some belief but the laying down of a requirement, the requirement of logical analysis. We do make sense, our propositions do stand in logical relations to each other. And such-and-such is required for that to be so. The metaphysics there is not in something other than language and requiring that it be like this or like that: that sort of metaphysics the Tractatus uses only ironically: it uses apparently metaphysical sentences, but in a way which is disposed of by the sentences which frame the book, in the Preface and the final remarks. The metaphysics of the Tractatus - metaphysics not ironical and not cancelled - is in the requirements which are internal to the character of language as language, in their [there] being a general form of sentence, in all sentences having this form. The metaphysics of the Tractatus is a kind of metaphysics that does not involve what is unsayably the case outside language, except so far as sentences which, as one might say, 'appear to be about such things' help us understand the requirements which are internal to a sentence's having a use. ${ }^{74}$

The following metaphysical commitments (underlying the conception advanced in the Tractatus of how the activity of clarification must proceed) are all touched on here:

- The logical relations of our thoughts to each other can be completely shown in an analysis of our propositions.

- These relations can be displayed through the employment of a logically absolutely perspicuous notation.

- Through the employment of such a notation, it is possible for propositions to be rewritten in such a way that the logical relations are all clearly visible.

- A proposition must be complex. ${ }^{75}$ 
- $\quad$ Every proposition can be analyzed. ${ }^{76}$

- There is such a thing as the logical order of our language.

- Antecedent to logical analysis, there must be this logical order - one that is already there awaiting discovery - and it is the role of logical analysis to uncover it.

- By rewriting them in such a notation, what propositions our propositions are will become clear. ${ }^{77}$

- By rewriting them in this way, it will also become clear what all propositions have in common.

- There is a general form of proposition and all propositions have this form.

- In its thus becoming clear what propositions essentially are, it will also become clear how misleading their appearances are - how much the outward form disguises the real hidden logical structure.

- A logically perspicuous notation is the essential tool of philosophical clarification.

- Through our inability to translate them into the notation, despite their resemblance in outward form to genuine propositions, certain strings of signs can be unmasked as nonsense (i.e. as strings in which signs to which no determinate meaning has been given occur).

- All philosophical confusions can be clarified in this way.

- By demonstrating the significance of this tool and its application in the activity of clarification, the problems of philosophy have in essentials been finally solved.

This list could be extended to include the following related commitments - to mention only a few of the relevant candidates:

- All inference is truth-functional.

- Logical analysis will reveal every proposition to be either an elementary proposition or the result of truth-operations on elementary propositions.

- There is only one logical space and everything that can be said or thought forms a part of that one space.

And so on. ${ }^{78}$

The italicized expressions in each of the above propositions indicate the occurrence of a moment of (what would count by later Wittgenstein's lights as) metaphysical insistence - a moment in which a requirement is laid down. The metaphysical commitments at issue here are, however, not of a sort that early Wittgenstein, at the time of writing the Tractatus, would have taken to be metaphysical. Indeed, most of them would not have been taken by him to be theoretical commitments at all, let alone ones that were somehow peculiarly his. Rather, he would have regarded them as pertaining to matters that become clear through the process of clarifying propositions, and, in particular, through the adoption and application of a perspicuous notation - a notation that enables one to avoid 
'the fundamental confusions' ('of which the whole of philosophy is full'; §3.324) by furnishing an absolutely clear way of expressing thoughts. ${ }^{79} \mathrm{His}$ aim, in writing that book, was to bring metaphysics to an end; and the method of clarification he thereby sought to practice, to achieve that end, was to be one that was itself free of all metaphysical commitments. The following remark nicely sums up his later view of his earlier situation with regard to these commitments:

We now have a theory, a 'dynamic theory' of the proposition; of language, but it does not present itself to us as a theory. For it is the characteristic thing about such a theory that it looks at a special clearly intuitive case and says: 'That shews how things are in every case; this case is the exemplar of all cases.' - 'Of course! It has to be like that,' we say, and are satisfied. We have arrived at a form of expression that strikes us as obvious. But it is as if we had now seen something lying beneath the surface. ${ }^{80}$

This passage points to a profound discontinuity in thinking that is folded within a fundamental continuity in Wittgenstein's philosophy that we have sought to bring out in some of our writings, and that has led Williams to assume that we must therefore be generally committed to downplaying any possible discontinuities in his thinking. The fundamental continuity in question lies in Wittgenstein's seeking, early and late, to find a way to do philosophy that does not consist in putting forward philosophical theses, and yet which (through the practice of methods of clarification that he, early and late, sought in his writing to exemplify) would genuinely enable his reader to pass from a state of philosophical perplexity to a state of complete clarity in which the philosophical problems completely disappear. The fundamental discontinuity in question lies in his later thinking that there was an entire metaphysics of language embodied in his earlier method of clarification, thereby illustrating that the most crucial moments in the philosophical conjuring trick are the ones that are apt to strike one as most innocent; so that it turns out to be much more difficult to avoid laying down requirements in philosophy than his earlier self had ever imagined. Hence it turned out that an entirely different approach to philosophical problems from that practiced in the early work was required and had to be developed in the later work.

The fundamental discontinuity in question here cannot be properly located if one begins by seeking to identify the explicit doctrines that early and later Wittgenstein each self-consciously seek to advance and defend in their respective writings. Arguably, part of the way that standard readings first developed was by commentators attributing to the Tractatus a great many of the doctrines that later Wittgenstein was centrally concerned to criticize. Many of these commentators, in turn, were often themselves authors of books on Wittgenstein that had some early chapters on the Tractatus in which a reading of that work was developed that allowed it to figure as a target for the most important philosophical criti- 
cisms advanced in Philosophical Investigations: criticisms of ostensive definition, privacy, solipsism, etc. (Over the years, a number of scholars have gradually discredited a great many of these attributions. Among some of the earlier casualties - to pick out just three episodes in this long and ongoing saga - were the baptismal theory of naming, the ghost-in-the-machine conception of thought, and metaphysical realism about objects and states of affairs.) No schema of the form 'early Wittgenstein believes $p$ and later Wittgenstein believes not- $p$ ' can ever serve adequately to represent the manner in which Wittgenstein's philosophy develops - not just because adherence to such a schema leads one to focus on a great many incorrect candidates for what early Wittgenstein actually held, but, above all, because such a schema invites us to look for the discontinuities in his philosophy in the wrong place.

For the crucial moments in the philosophical conjuring trick performed by the author of the Tractatus are ones that are performed by him on himself. They take place at a stage prior to any at which he imagines the activity of propounding substantive philosophical doctrine to begin. Thus, throughout his later work, Wittgenstein is pervasively concerned to practice a method of philosophical investigation that enables us to locate those moments in our thinking in which, unbeknownst to ourselves, we first broach philosophical ground - those moments in which, though nothing beyond the obvious seems yet to have been asserted, a note of metaphysical insistence has already crept in and an unwarranted requirement on how things must be has been laid down. One will not fully appreciate the bearing on his early work that later Wittgenstein takes such a method of investigation to have, if one fails to appreciate the extent to which (what he later regards and criticizes as) the central philosophical doctrines of the Tractatus were of such a sort that they were able to appear to its author, at the time of writing, not to be 'philosophical doctrines' at all: they were able to appear utterly innocuous and altogether innocent of metaphysical commitment. If we fail to appreciate this about the Tractatus - if we fail to understand the radically anti-doctrinal character of the author's undertaking in that book - and look instead for explicit doctrines of the sort we would look for in other books, then most of what we will readily identify as its central doctrines are ones that serve as the central targets of the early (as well as the later) work; and they will turn out to be couched in the very propositions that are earmarked as the ones we must overcome if we are to understand the author of the work. Thus we will be led into the dead-end of the standard sort of reading that we discussed above, in section 2. It is interesting in this connection to note how many of the doctrines of the sort that standard readers ascribe to the Tractatus and that resolute readers are committed to rejecting - such as 'the doctrine of showing', the commitment to the existence of ineffable truths, and various optional subsidiary doctrines (such as realism, mentalism, solipsism, etc.) and optional subsidiary commitments (such as a distinction between grasping and 'grasping', saying and 'conveying', etc.) - never figure in any of the passages in Wittgenstein's later writing where he is explicitly concerned to criticize something he identifies as a 
questionable philosophical commitment actually held by the author of the Tractatus. ${ }^{81}$ What figure in such passages instead are the sort of metaphysical commitments listed in the passage from Diamond quoted above - commitments that later Wittgenstein came to think do indeed presuppose a theory but that early Wittgenstein was able to think merely fell out of the activity of clarification itself. $^{82}$ He thought that they could be exhibited through the practice of that activity, and were not commitments to any substantive theory.

One very common sort of criticism of resolute readings (that we have not discussed above) rests upon a failure to distinguish between these two importantly different sorts of theoretical commitments. In the absence of such a distinction, it is bound to seem painfully easy to criticize resolute readings on the basis of putative external 'evidence' drawn from Wittgenstein's later writings: in order to sink a resolute reading, all one needs to do is to find a passage somewhere in Wittgenstein's later writings that criticizes a substantial philosophical commitment that he identifies as essential to the program of philosophical clarification that the Tractatus seeks to practice. Such passages cease to appear to be embarrassments to resolute readings, however, as soon as it becomes clear that it is open to resolute readers to regard the Tractatus (as Diamond evidently does in the passage quoted above, and as later Wittgenstein evidently did) as a paradigmatic expression of the metaphysical spirit in philosophy. Once this becomes clear, the task of criticizing resolute readings ought to begin to seem a somewhat more delicate and difficult (and hopefully also a somewhat more interesting and rewarding) enterprise than it has sometimes seemed to some of our critics. For it will not suffice merely to collect passages in which later Wittgenstein is criticizing early Wittgenstein in order to criticize a resolute reading; one needs to devote enough attention to each passage in which such a criticism figures to be able to make out what is being criticized and what sort of criticism it is that is there being entered. ${ }^{83}$ There is certainly nothing wrong with looking to remarks about the Tractatus in Wittgenstein's later writings for a source of possible evidence in weighing the merits of alternative readings of his early book. But reliance on such remarks cannot serve as a surrogate for having an independently philosophically coherent and textually plausible account of what he was up to in the Tractatus. And, whenever one does wish to adduce external evidence of this sort for or against a particular reading, then it must be pondered and weighed (rather than merely adduced as self-evidently devastating).

We cannot enter here into a consideration of the many passages in Wittgenstein's later writing that might offer us additional 'external' clues as to how he might have understood what he wanted to be doing in philosophy at the time of having completed the Tractatus. (It would take a paper considerably longer than the present one to sift and assess even a small fraction of the evidence here at all responsibly.) The task is rendered somewhat more arduous than is sometimes appreciated by the fact that in his later writings Wittgenstein is primarily concerned to bring out what is wrong in his earlier way of thinking; he is not primarily concerned in such passages, for example, to highlight continu- 
ities in his philosophy. (Though if one is on the lookout for them, when reading other remarks in his later writings, then a great many of them are hard to miss.) His aim, generally, when later reflecting on one or another aspect of his earlier way of thinking, is to try to pinpoint its philosophical Achilles' heel. One therefore needs to handle such retrospective comments in his later writings with some care, if one wishes to tease out of them a portrayal of what his earlier way of thinking might have been, such that it would have had the power to captivate a philosopher with his high standards of rigor and clarity, with his determination to think things through to the bloody end, and with his desire not only to avoid but to put an end to metaphysics. We would, nevertheless, like to conclude with the following suggestion: an appeal of a resolute reading is that it may be able to make good sense of why Wittgenstein is concerned to focus on precisely those commitments that he does single out for criticism, in the passages in his later work where he is actually occupied with the task of criticizing the Tractatus (and thus also of why he is not drawn to mention the Tractatus when singling out for criticism in his later work just the sorts of views that resolute readings are committed to not ascribing to that work). Thus not only is it not a part of resolute readings, as such, to defend any version of an excessively strong continuity thesis (of the sort, for example, that Williams attributes to us), but, on the contrary, it can be a central motivation of such readings (and is a central motivation of our readings) to try to improve upon existing accounts of the discontinuities in Wittgenstein's philosophy by furnishing a reading of the early work that affords a more promising background for a textually satisfying and philosophically nuanced account of where the real discontinuities lie.

\section{Notes}

1 After some correspondence on the topic, Ogden and Wittgenstein settle on 'to make propositions clear' as a translation of das Klarwerden von Sätzen; Pears and McGuinness render it as 'the clarification of propositions'. Neither of these renderings is ideal; each has something in its favor. We employ both. Wittgenstein's original understanding of this activity of 'making clear' or 'clarification' is a guiding topic of this paper.

2 The characterization of such a reading as 'resolute' is first due to Thomas Ricketts and first used in print by Warren Goldfarb in his 1997, at p. 64; cf. also p. 73, note 10.

3 Meredith Williams speaks not of 'resolute readings' but of 'the austere reading'.

4 To mention only some of the most notable cases, and leaving to one side anyone who has ever been a student of either of us, the following scholars have all written articles that advance readings of Wittgenstein's work that (seem at least to us) clearly to qualify as resolute in the sense adumbrated below: Piergiorgio Donatelli, Juliet Floyd, Warren Goldfarb, Martin Gustafsson, Michael Kremer, Oskari Kuusela, Thomas Ricketts, and Matt Ostrow. Yet we find that we have local - and in some cases quite deep disagreements with almost all of these scholars. (And each of them would probably be able to say the same thing about the relation of their work on the Tractatus to that of almost all of the others.) Then there are many cases that are not so clear, but no less noteworthy: there are scholars - such as, for example, Eli Friedlander, Hidé Ishiguro, Marie McGinn, Brian McGuinness, and the late Peter Winch - whose read- 
ings are very different from each other and each of whom would seem to fall into 'the enemy camp', if the battle lines are drawn in ways our critics have often sought to draw them; but about each of these readings it is by no means so clear (at least to us) whether or not it is right to think of the reading in question as belonging in a box together with resolute readings. If there was perhaps fairly recently still a time when it made sense to think of there being something like a standard sort of reading of the Tractatus and a handful of dissenters, those days are now certainly over. There is an increasing variety of genuinely interesting ways to dissent on offer. Anyone seriously interested in coming to understand the book stands to gain from this diversity of readings of the Tractatus. For each such reading can help shed light on the strengths and limitations of the others and thus on various aspects of the text itself. The sooner the present controversy concerning the interpretation of the Tractatus advances past the stage in which the most pressing question appears to be one about which of two 'camps' one ought to belong to, and the sooner it comes to be focused on detailed questions concerning how the text is best read, the more progress can be attained in achieving a genuine understanding of this extraordinarily difficult book.

5 Peter Sullivan makes this basic point forcefully in his 2002. But he does so with some misplaced polemical animus, partly because he sees the schematic character of their claims about how to approach the text as posing a problem for resolute readers, rather than merely indicating how much remains to be done, in the way of understanding the text, once a commitment to undertake to read the work resolutely is in place. To undertake to read the work resolutely means nothing more than to undertake to read it in a certain way - and thus to introduce certain constraints on what will count as an acceptable reading (and, in particular, on what will count as having thrown away the ladder). But to commit oneself to reading the text in such a way is not yet to have a reading, if what one means by 'having a reading' is to have a full story about each of the rungs of the ladder and each of the transitions from one rung to the next. Some of Sullivan's polemical animus seems simply to rest here on a misunderstanding of how much we think is accomplished by merely getting clear about the basic commitments of the text insisted upon by a resolute reading, as such. Our suggestion that the text has these basic commitments has met with fierce opposition (as evidenced, for example, by the essay by Meredith Williams to which we reply below). So the debate has had a tendency to become bogged down over extremely elementary questions. But we agree with Sullivan that if the debate over whether the text has these commitments were settled in favor of the resolute reading, many interesting questions (about how to understand the details of the dialectic that is meant to drive the reader up the ladder) would remain to be worked out. But what does it mean to go on and 'work out' these details? Part of what may fuel Sullivan's dissatisfaction here is a further commitment on his part to a very particular conception of what would count as 'really having a story' about how the Tractatus works. We take these issues up briefly in section 4 of this paper.

6 When we speak here of 'propositions', we are translating Wittgenstein's 'Sätz'. The term 'Satz' in the Tractatus floats between meaning (1) a propositional symbol (as, e.g., in $\S \S 3.3 \mathrm{ff}$ and $\S \S 4 \mathrm{ff}$ ) and (2) a propositional sign (as, e.g., in $\S \S 5.473 \mathrm{ff}$ and $\S 6.54)$. It is important to the method of the Tractatus that the recognition that certain apparent cases of (1) are merely cases of (2) be a recognition that the reader achieve on his own. Consequently, at certain junctures, the method of the Tractatus requires that the reference of 'Satz' remain provisionally neutral as between (1) and (2). Many of our uses of the terms 'proposition' and 'sentence' will be correspondingly neutral.

7 The ascription to Wittgenstein of (what Conant has called) 'an austere conception of nonsense' is therefore only a corollary of this second feature of a resolute reading. Commitment to 'austerity' involves the rejection of a particular conception of nonsense (see, e.g., $\$ \$ 5.473-5.4733$ ) that the Tractatus is particularly concerned to 
reject - one that many subsequent readers, starting with Carnap, have been particularly concerned to ascribe to that work. But, contrary to what some of our critics have claimed, we do not take a commitment to 'austerity' to constitute any more than that. We shall return to this issue in section 4 .

8 Thus, for example, by placing great emphasis on certain remarks from Diamond's essay 'Throwing Away the Ladder' (in Diamond 1991), while misinterpreting those remarks, Meredith Williams manages to convince herself that Diamond seeks to ascribe to the Tractatus a theory of sense - a theory which allows one, for example, to determine that a particular propositional sign is meaningless by ascertaining that it has failed to meet a condition of bipolarity set forth by the theory. (One therefore finds Williams attributing to Diamond forms of argument that can be summarized as follows: 'The bipolarity condition for sentencehood is violated because if this sentence is meaningful, it is necessarily true.') But what really leads Williams to this reading of Diamond is her antecedent conviction that any reading of the Tractatus must ascribe to its author a commitment to some such theory or other. So the only interesting question in this area for Williams is (not whether Diamond and other resolute readers subscribe to some such theory, but rather) which theory it is they rely upon. We shall return to this issue in section 3.

9 Peter Sullivan, for example, as we shall see below, is concerned to present a very different sort of criticism of resolute readings. So, too, is Marie McGinn; see, for example, her 1999.

10 In what follows, we are replying to Williams's 'Nonsense and Cosmic Exile: The Austere Reading of the Tractatus' and Sullivan's 'What is the Tractatus About?' both published in the present volume. This paper is not intended to be a general reply to our critics. Nothing of the sort is possible. (Those who imagine that such a thing ought to be easily possible, and that we should get on with it, seem to imagine that there is some straightforwardly surveyable set of points that unites all of our critics in their opposition to our reading. But we have not found this to be the case.) A host of different sometimes relatively straightforward misunderstandings, and sometimes notso-straightforward points of disagreement, crop up in discussions of this topic. Indeed, often the disagreements cut across the supposed party lines that divide resolute and non-resolute readers. (Thus, for example, though Williams and Sullivan are united in their dissatisfaction with 'the' resolute reading, many of the points that Williams adduces as grounds for opposing a resolute reading place her, as far as we can ascertain, no less at odds with Sullivan's reading than with any put forward by a self-identified resolute reader.) We do hope in our remarks here, however, to make progress in clearing up at least some of the most prevalent misunderstandings abroad regarding our way of reading the Tractatus. We are very grateful to the editors of the present volume for providing us with this excellent forum in which to do so. We regret that discussion of other remaining significant misunderstandings and interesting points of genuine disagreement will have to wait yet another occasion.

11 The passage runs as follows:

'Language (or thought) is something unique' - this proves to be a superstition (not a mistake!), itself produced by grammatical illusions.

And now the impressiveness retreats to these illusions, to the problems.

(Philosophical Investigations, §110)

The tendency of thought here at issue, Wittgenstein says, 'proves to be a superstition (not a mistake!)'. Tolerance of contradiction would involve a tolerance for (what Wittgenstein here calls) 'mistakes'.

12 See Conant 2003 and Diamond forthcoming B for further discussions of this topic. 
13 It is worth taking a moment to say, in case it is not clear, that our remarks here are by no means directed at Williams alone. It is not at all uncommon for proponents of standard readings to attempt to cover up the problems with their readings by ascribing to early Wittgenstein a quite remarkable tolerance for incoherence - a tolerance that simply does not fit with his clear willingness to treat apparent counter-examples with care and seriousness, as comes out in his treatment of 'A believes that p', and of the incompatibility of color ascriptions with each other. The word 'paradox' is misused if it is pasted on to a reading that simply stops at the point at which serious questions arise about how Wittgenstein is supposed to have thought about the deep-going incoherence to which the reading appears to commit him.

14 Lectures on the Foundations of Mathematics, p. 18.

15 This way of picturing of 'the limits of logic' begins to run into trouble as soon as one begins to try to think it through. One is led to ask what it would be to 'move into' the realm outside the limit if it wasn't thinking in the realm outside the limit. 'Move' is a metaphor for doing what? Grasping what's out there without actually thinking it? Standard readings of the Tractatus often try to buy some wiggle room here by characterizing what is involved in transgressing the limits of logic more circumspectly, hence not as 'thinking what's outside the limit', but rather as attempting to think it (e.g. by attempting to say what's outside the corresponding limit of language). But one runs out of wiggle room quickly here.

16 For further discussion of this (quasi-geometrical) picture of 'the limits of thought' and early Wittgenstein's criticisms of it, see Conant 1992.

17 See Conant 2002: notes 4 (p. 425), 22 and 23 (p. 429), 27 (p. 430).

18 See especially the wording of her description of what she takes Diamond to deny, and what she herself accepts, namely that there is a doctrine of showing in the Tractatus, according to which Wittgenstein tries to intimate truths about reality and language that cannot be said. This suggests that there is an elaboration of (something called) 'a say/show distinction' in the book to which she is especially attuned but which Diamond is forced to overlook or deny. But there simply is not, in anything that Wittgenstein says in the book about saying and showing, anything that has a clear connection with 'intimating truths about reality and language' through the production of nonsensical sentences. Williams repeatedly suggests the opposite, but with no textual basis. To insist (as, for example, Conant has in 'The Method of the Tractatus') that one needs to distinguish between showing and elucidating is not to deny that there is a distinction between showing and saying in the book. (We return to this issue in section 3.) It is only to deny that what commentators have mostly taken the distinction between saying and showing to be - and, in particular, what they have taken 'showing' to be - is in the book. One might want to say, in expounding what the Tractatus calls 'showing', that 'Jamie the Zebra has died at the Zoo' shows that it is about Jamie ( $\$ 4.1211$ : 'Thus a proposition " $F a$ " shows that in its sense the object $a$ occurs'), or that it shows what it says to be so ( $\$ 4.022$ : 'The proposition shows how things stand, if it is true'); but, if that sort of case exemplifies 'showing', we are exactly nowhere, so far, in understanding how 'The world is everything that is the case' illuminates anything. That the sentence about the zebra might be said to show this or that depends on the senseful use of the signs in it; a sentence the signs in which are not used sensefully, and in which the use is not a 'canceling out' sort of use exemplified by tautologies and contradictions, is one which does not show anything in the sense which is exemplified by the zebra example.

19 There are passages which suggest that Williams means by 'the doctrine of showing' something roughly like this: a sentence like 'The world is everything that is the case' cannot, according to the theory of meaning in the Tractatus, be held to say what it appears to say, but it can nevertheless be held to illuminate or to show what one had 
taken it to be attempting to say. But that view certainly cannot be found in the passages in the Tractatus which concern 'showing'.

20 This is not the only problem. Any such story (even a rough story) of how the meaningless propositions convey insights would have to depend either on considering the signs in the proposition or on considering the symbols, and there does not appear to be any way of constructing such an account which would not provide a disproof (by counterexample) of views about signs and symbols to which Wittgenstein would have to be taken to be committed, so it would seem, on standard readings. This point would apply also to the interpretation of the 'doctrine of showing' that we discuss in the previous note.

21 A further part of the problem here is that it is difficult to see how there could be even a rough story, of which Wittgenstein might have availed himself, about how specific meaningless sentences are tied to specific insights which is not a story about what the sentences in question mean - and, if so, that would provide another big dose of 'paradox', otherwise known as incoherence.

22 How are we to square these consequences with, for example, §4 ('The thought is the significant proposition') and the many related sections? If it were to be suggested that Wittgenstein accepted two quite different senses of 'thinkable', so that the insights of his book were, in one sense, not thinkable, but were thinkable in some other sense, how is this supposed to be got out of the text? Is it supposed to come out of the 'doctrine of showing'? How, then, does that 'doctrine' do such work? There is in such a suggestion a measure of desperation.

23 How are we to square these consequences with, for example, $\S 4.024$ ('To understand a proposition is to know what is the case, if it is true') and the many related sections? Shall we now multiply senses of 'understanding'? This multiplication game, once begun, will have to go on to encompass multiple senses of the expressions 'inferring', 'judging', and so on, across the entire spectrum of expressions for the exercises of logical capacities.

24 For an interesting discussion of a further problem that the standard sort of reading runs into here, as soon as it attempts to take the conception of logic put forward in the Tractatus at all seriously, see Warren Goldfarb's article 'Das Überwinden: AntiMetaphysical Readings of the Tractatus' (in preparation). Goldfarb argues that, if showing is a kind of communication, then there is a kind of content that is showable, and logical truths (if they are able to show) must partake of such content. He then goes on to argue that this would undo what Wittgenstein thought he had accomplished by making clear that logic has no content - that a proposition of logic is sinnlos and that 'theories that make a proposition of logic appear contentful [gehaltvoll] must be false’ (\$6.111).

25 These four objections are by no means entirely independent of one another, as will become clear in our discussion of them below. Each depends to some extent on the other three, and the first two are really two facets of one single extended misunderstanding.

26 The other main source of this misconception stems from her assumption that resolute readers must be operating with a covert theory of nonsense. A proper response to the 'you, too' argument must therefore come in two parts, addressing both her misreading of what an austere conception of nonsense involves and her misunderstanding of what sorts of theoretical commitments it depends upon.

27 Diamond 1991, pp. 195-7.

28 Conant 2002, p. 423.

29 It is worth mentioning that the view that Williams here attributes to us is one that some commentators on the Tractatus have held. See the references to Proops and Anscombe below. 
30 The preceding paragraph has been lifted from Diamond's article 'Criss-cross Philosophy' (forthcoming D) where this topic is discussed at greater length.

31 We are drawing here on remarks in 'Notes Dictated to Moore' (published in Notebooks 1914-1916, pp. 107-18); see p. 115.

32 Williams suggests that resolute readers take the context principle to provide grounds for a view of nonsense powerful enough to support diagnoses of philosophical sentences as violating conditions of meaningfulness. But the context principle is not taken by resolute readers to be the basis of any such account.

33 There is a passage in Williams's essay in which she seems to suggest that Diamond's point would be that 'A is an object' is nonsense, if 'A' has the meaning it has in other contexts in which it has meaning, and if 'object' has the use it usually has. Williams gives something like that as Diamond's account of why "Caesar is a prime number" is nonsense': supposedly, if the personal name and number predicate mean what they do elsewhere, then the sentence is nonsense. But that is not Diamond's view, either of 'Caesar is a prime number' or of 'A is an object'. There is, according to resolute readings, no 'if thus-and-such is what the words mean, then the sentence is nonsense' or 'then the sentence is a syntactic mess'.

34 To claim, as we do here, that the activity of truth-functional analysis was taken by early Wittgenstein 'not to depend on any theory of language put forward in the book' does not in any way preclude us, qua resolute readers, from also being able to claim that early Wittgenstein was mistaken about this and that later Wittgenstein came to appreciate this. We return to this topic in section 5.

35 We borrow this term from Goldfarb 1997.

36 Some scholars who have some sympathy with our reading of the Tractatus have misunderstood us on this point and have taken this alone to mark a sufficient reason for thinking there must be 'a third way'; and some who have sought to defend us in print have also misrepresented our view on this matter. Conant, for example, in a number of his recent writings, in order to avoid misunderstanding on this point, has carefully distinguished between showing (in scarequotes) and showing (simpliciter) - always using only the former to refer to the sort of 'gesturing' standard readers take Tractarian nonsense to be able to do and always using only the latter to refer to that which the Tractatus itself takes senseful, tautologous and contradictory propositional symbols to do. But it is striking how many of Conant's readers, on both sides of the debate, take his criticisms of the former to constitute a rejection of the latter - as if the mere idea of showing itself already presupposed an implicit commitment to the idea of there being something ineffable which is thus shown. But this still cannot entirely explain why people who are not inclined to acquiesce in a standard reading have taken resolute readers either to reject or at least to be suspicious of the very idea of 'showing' (see e.g. Sullivan 2002, pp. 49-52). Part of the explanation, no doubt, is that so much energy has been directed by resolute readers towards absolving Wittgenstein of any commitment to (what Williams calls) 'showing' (as something that nonsense can do) that it has directed attention away from the topic of (what Wittgenstein calls) showing (and other topics that are not directly tied to the topic of nonsense).

37 Diamond 1991, p. 198.

38 Conant 2002, p. 424.

39 As we have seen, Williams's version of a standard reading (like many others) fails on both of these counts; textually more sensitive versions of a standard reading fail only on the second count.

40 A proper treatment of this topic would obviously require considerably more space than we can afford to devote to it here. All our brief remarks in the next paragraph are meant to do is to underscore the main point of the present paragraph (namely, that resolute readings, as such, are not committed to throwing away the distinction 
between saying and showing) by indicating how the distinction can be developed in a manner that is consistent with the core commitments of resolute readings.

41 We are, of course, not here denying that speaking about some subject matter requires knowledge of content pertaining to that particular subject.

42 Goldfarb 1997, p. 66.

43 The remark in question occurs in Diamond 2000 at p. 165.

44 Conant 2002, p. 378.

45 To mention only one example, he points out (in Sullivan 2002, pp. 46-9) that certain resolute readers have evinced a special hostility to explanations of features of language via an appeal to features of reality, but have seemed to evince a greater tolerance towards the reverse order of explanation, thus making it seem as if resolution had something 'particularly to do with repudiating a certain sort of realism' (p. 47). This is an astute observation about a tendency that is in the literature. (It has, no doubt, something to do with the etiology of certain resolute readings in a prior rejection of certain realist readings.) A resolute reading should be equally committed to rejecting explanation in either direction here and therefore should not accord realism any privileged status as the target of criticism.

46 Sullivan characterizes 'the core commitments' of 'the' resolute reading as follows:

Resolution's first commitment is a view of what nonsense is and what it cannot be: nonsense is a failure to make sense; it cannot be a matter of making the wrong kind of sense ... Wittgenstein presents this view of nonsense at TLP 5.4733ff ... Adapting terminology of Conant's, I'll call commitment to this view of nonsense 'austerity'. The second element of resolution is a 'full-hearted recognition' that when Wittgenstein describes his own propositions as 'nonsense' his meaning is that they are nonsense in the only way the austere view of TLP 5.473ff allows, that they fail to make sense.

(Sullivan 2002, p. 45)

Sullivan then goes on to say: 'The two components of resolution so far introduced are, I believe, clear ... and clearly correct' (p. 46). It is perhaps worth noting, however, that his characterization here of the view of nonsense that resolution rejects is merely the corollary identified above of (what we call in section 1) the second feature of a resolute reading. It is difficult to square some of the things Sullivan says in criticism of resolute readings with a whole-hearted endorsement on his part of the second feature in its full generality (and not merely the particular corollary of it that is at issue in $\S \S 5.4733 \mathrm{ff}$ and that Sullivan dubs 'austerity').

47 Thus, as Sullivan rather charmingly sums up his attitude: 'Some writers in the field have reacted to the resolute reading with an outraged, "No! But surely ...!" My own reaction, at least to its core ideas, is better captured, "Well, yes, so far. And now ...?", (Sullivan 2002, p. 44).

48 Sullivan does think that, along the way, in their zeal to make it seem that what they have offered can amount to a reading, resolute readers also do make some positive mistakes, engaging in specific interpretative moves that he thinks involve specific misinterpretations of the text.

49 Sullivan, for example, complains: ' $[\mathrm{A}] \mathrm{s}$ a guide to interpretation, the austere view of nonsense is too undiscriminating' (2002, p. 62). We agree. We think the austere view of nonsense is an important thing to be clear about (if you want to understand what Wittgenstein is up to in the book); but we don't think that once you've gotten clear on this one matter, you're home free (so that, merely by coming to see that Wittgenstein rejects the sort of conception of nonsense that is usually attributed to him, one has thereby furnished oneself with anything that deserves to be termed 'a guide for inter- 
pretation' on any very weighty understanding of the sort of guidance such a 'guide' ought to supply).

50 We do think that Sullivan 2002 contains a number of such misunderstandings of Conant and Diamond.

51 In Sullivan's example, $\mathrm{P}$ and $\mathrm{Q}$ are propositions described in such a way that $\mathrm{P}$ does indeed entail Q.

52 Goldfarb's discussion of these passages in 'Metaphysics and Nonsense' builds on Thomas Ricketts 1996; see especially pp. 88-94).

53 That the author of the Tractatus thinks there is a kind of double-think inherent in philosophical discourse we do not dispute. What we dispute is that he thinks that it is (something describable as) 'the system' which enables us, in a fairly direct way, to see that there is a kind of double-think inherent in philosophical discourse.

54 Many philosophers do read the Tractatus in exactly this sort of way; for example, both Anscombe and Proops take it that we are meant by the book to come to identify certain propositions as problematic by recognizing that they are not 'bipolar'. See Proops 2002, p. 300; and Anscombe 1963, p. 85.

55 Sullivan 2002, pp. 50-1.

56 Michael Kremer (2002) discusses in detail issues that we cannot touch on here, including the application of the term 'Bedeutung' in connection with expressions joined by an equals sign. We are greatly indebted to Kremer for comments on our treatment of ' $\mathrm{P}$ entails $\mathrm{Q}$ ' in an earlier draft, as well as for conversations and correspondence on numerous other topics discussed in this paper.

57 For a discussion of why these various topics are all grouped together in the 6s (along with the topics of ethical and philosophical uses of language), see Diamond forthcoming A and Conant 2004.

58 The number of Ts and the number of terms in the final parenthesis are determined by the number of propositions that we need to reach in an analysis of $\mathrm{P}$ and $\mathrm{Q}$ in order for the entailment to be set out as a truth-table tautology. That any entailment can be so written is built into the method of clarification; this is a feature of the Tractatus which Wittgenstein did not take, at the time of writing the book, to reflect a substantial doctrine, but about which he changed his view.

59 Many commentators have taken the expressions 'Unsinn' and 'Scheinsatz' to be synonyms in the Tractatus - as they often are in the writings of Carnap and other members of the Vienna Circle who were influenced by the Tractatus. But this assumption leads to trouble when one tries to interpret many of Wittgenstein's remarks in the 6s. For the Tractatus, any propositional sign that is Unsinn is a Scheinsatz; but the converse does not hold, as the treatment of mathematical propositions makes especially clear.

60 For a particularly nice example of a case in which a very good philosopher allows herself to take someone to be producing nonsense, when he is simply using words in a way that is different from what she expects, see Anscombe 1963, p. 85. She imagines her way into what she takes to be the nonsensical ambition of Flew, and does not pause to ask whether there is not some way of taking his words which she might recognize to be intended by him, which makes his claim senseful and indeed correct, though poorly expressed. Diamond discusses this example in her forthcoming C.

61 Sullivan 2002, p. 75, note 28; cf. also p. 62.

62 It is worth noting that, however appropriately such a charge may be leveled at its lowest exemplars, it is not clear that 'pernicketiness' need characterize the practice of (anything properly termed) 'ordinary-language philosophy' as such. For a characterization of that practice that is not open to such a charge, see either the opening pages of Cavell 1976 or the title essay in the same volume.

63 Sullivan justifies this reading of the passage, in part, through a particular understanding of how to construe the 'always, whenever' when Wittgenstein says: 
The right method of philosophy would be this: To say nothing except what can be said, ... and then always, whenever someone wished to say something metaphysical, to demonstrate to him that he had given no meaning to certain signs in his propositions.

Sullivan says: '[T] he method is to be triggered "always, whenever" - that is, as soon as - "the other" indulges his inclination towards philosophy' (2002, p. 62).

64 It seems to be part of Sullivan's picture of what resolute readers hold that they will be disinclined 'to allow', as he puts it at one point, 'the train of nonsense to develop under its own momentum' (2002, p. 62) - that they, like the practitioner of $\$ 6.53$ (on his reading of the remark), will not be able to keep themselves from pouncing. But, on our reading of the Tractatus, it is essential to its method of clarification that one not pounce and that the train be allowed to roll. Indeed, not only do we not have any interest in cutting off the philosophical dialectic prematurely, as Sullivan suggests, but we are worried that, contrary to his own intention, Sullivan's proposals (for how to bring 'the system' to bear on particular putative examples of philosophical nonsense) may have just this effect. As we indicated above (in our discussion of the topic of the philosopher as would-be 'spotter' of philosophical illusions), one of our worries about Sullivan's account is that it threatens to make it seem easier to 'spot' philosophical nonsense than Wittgenstein thought it could be.

65 We do not hereby mean to claim that the Tractatus itself adheres to (what $\$ 6.53$ calls) 'the only strictly correct method' in philosophy. For further discussion, see Conant 2002 , note 131 .

66 This is not to deny that such ascriptions may serve a genuinely elucidatory purpose in attempting to achieve clarity about what leads one to say certain things in philosophy, and therefore that such ascriptions can play an important role in characterizing some of the philosophical targets of the Tractatus.

67 Warren Goldfarb makes this same point forcefully in 'Das Überwinden'.

68 We therefore concur with Goldfarb in holding that a 'piecemeal' approach is required to understanding how the book undermines its own propositions.

69 And a further question that sometimes divides them is the following: how important is that question to an understanding of later Wittgenstein? How important it is to arrive at an accurate account of Wittgenstein's original self-understanding as author of his early work, in order to achieve an accurate appreciation of what he later thought was confused and self-deluded in his earlier self-understanding of what he had achieved in philosophy?

70 There is also a discussion of the significance of Wittgenstein's changed understanding of clarification, taken to be the aim of philosophy, in her forthcoming D.

71 See especially Kuusela 2003.

72 Diamond 1991, pp. 184-5.

73 We choose this example because it occurs in Diamond 1991, the text by a resolute reader that Williams most frequently cites.

74 Diamond 1991, pp. 18-19. In our list below of metaphysical commitments embodied in the Tractatus, we shall be using sentences of the sort that occur in this passage, sentences that 'appear to be about' the essential nature of language. We are not claiming that these sentences are anything but plain nonsense, or that Wittgenstein in any way intended to communicate a metaphysics of language. It was not until much later, when he had realized that his early conception of philosophical clarification had built into it a quite particular view of language, that he could recognize the metaphysical commitments for what they were.

75 It was, above all, in connection with this presupposition that Piero Sraffa's Neapolitan gesture of disdain (along with his query 'What is the logical form of this?') was able to 
do its picture-shattering work.

76 This commitment involves a great many subsidiary commitments about the character of the process of analysis, about such a process presupposing a point at which the analysis terminates, about when such a point is reached, about what is thereby disclosed, etc.

77 There are a great many subsidiary commitments that come into play here as well, through the commitment to the idea of an absolutely perspicuous notation. That any entailment can be set out as a truth-table tautology, in the manner discussed in section 4, is one example of such a commitment (which, as we noted above, Wittgenstein did not take, at the time of writing the book, to reflect a substantial doctrine, but about which he changed his view).

78 Upon reading a draft of this paper, Michael Kremer pointed out to us that the precise nature of the metaphysical commitments listed goes a long way towards explaining why the first thing Wittgenstein wrote, upon returning to philosophy, was 'Some Remarks on Logical Form'. For that paper, despite all the defects that Wittgenstein almost immediately came to see in it, begins to unravel just these metaphysical requirements.

79 That is, early Wittgenstein fails to realize that the very idea of 'an absolutely clear way of expressing thoughts' itself represents a substantial metaphysical commitment. For an illuminating discussion of this idea, see Gustafsson 2003. We are grateful to Gustafsson for comments on a previous draft of this paper.

80 Zettel, §444. Oskari Kuusela (forthcoming) quotes the following essentially identical remark from the Nachlass, which he suggestively retranslates as follows:

We have a theory ... of the proposition; of language, but it does not seem to us a theory. For it is characteristic of such a theory that it looks at a special, clearly intuitive case and says: 'That shows how things are in every case. This case is the exemplar of all cases.' ('Of course! It has to be like that,' we say, and are satisfied. We have arrived at a form of expression that strikes us as obvious. We have arrived at a form of expression that enlightens us.

(Ts220 §93/Ms142 §105)

Kuusela prefaces his citation of this passage by saying 'The following characterisation that Wittgenstein provides of his early philosophy ... suggests that he did not think he was putting forward a theory.' And, in going on to comment on the quotation, Kuusela remarks: '[A]lthough there is a theory of propositions, it is not recognised as one. Rather, it is as if we had caught a glimpse of something: as if we were directly perceiving the essence of propositions.' This nicely captures what we take to be Wittgenstein's later view of the character of his earlier unwitting entanglement in metaphysics.

81 One important difference between early and later Wittgenstein has, of course, to do with what he would regard as a substantial philosophical commitment - and hence with his later criticisms of his earlier commitments. But even where early and later Wittgenstein have a common target in their sights (and there are a great many such targets: mentalism, psychologism, solipsism, realism, idealism, ineffabilism, etc.), there is all the difference in the world in how the criticism is prosecuted. A great many of the most significant discontinuities in Wittgenstein's work therefore have to do not just with what comes in for criticism, but in what sort of criticism it comes in for. Every metaphysical doctrine criticized in the Tractatus must be treated again in the later work, only now in such a manner that the mode of 'interrogation' itself no longer presupposes a covert metaphysics. The aspiration to achieve such a philosophically presuppositionless mode of interrogation is common to the earlier and the later work, but its attainment comes to seem to later Wittgenstein to be an enormously more 
difficult matter than he had ever earlier imagined and to require an altogether different mode of philosophical composition - one which elicits an entirely different sort of engagement and cooperation on the part of a reader and in which the struggle to avoid philosophical assertion and commitment requires a far more circuitous and tentative manner of proceeding.

82 We are here disagreeing with certain resolute readers and, incidentally, thereby illustrating that a variety of resolute readings is, indeed, possible. Juliet Floyd, for example, has been concerned to advance (what she herself has dubbed) a Facobin reading - a reading that denies that the Tractatus is committed to the idea of a 'completely adequate' analysis, and a fortiori to the metaphysical commitments listed above that we take to be internal to its program of analysis. See, for example, Floyd 2002. We therefore feel obliged to reject some of what she offers as 'the best answer that can be given to those critics of Diamond (and other antimetaphysical readers of the Tractatus)' - namely, that, unlike Frege and Russell, early Wittgenstein 'does not think any notation can depict the grammar of language ... the logical order' (p. 340). The possibility of our disagreement with la Facobine, Floyd, on this fundamental matter furnishes a particularly vivid illustration of the extent to which the central features of a resolute reading (discussed in section 1) underdetermine a reading of the book as a whole.

A number of other resolute readers have favored such a Jacobin reading, including Rob Deans, Burton Dreben and Rupert Read, who has developed this sort of account in a series of recent articles. (We are indebted to Read for helpful comments and suggestions.)

83 Considerably more delicacy than just this is, in fact, required. It is quite mistaken to think that matters here can be settled simply by wheeling in a collection of passages from Wittgenstein (of, say, the form: 'I earlier thought ... but the problem with this is ...'; or: 'In the Tractatus, I held ..., but now ...') and dumping them on a reader, as if their sheer quantity alone could settle any interesting question on which resolute readers have taken a stand. The idea that one can mount a defense on behalf of standard readings simply by piling up such 'evidence', in the style of Johnny Cochrane, depends on the assumption that the collection of passages in question form a relevantly homogeneous category, so that no detailed interpretation of any individual exhibit is required - all that is required is some textual indication in each passage that later Wittgenstein is expressing some form of dissatisfaction with his earlier philosophy. In fact, on some of these lists of putative instances of external evidence adduced by our critics, there often figure a very heterogeneous collection of passages - only some of which are criticisms of commitments actually held by the author of the Tractatus. Not every such passage (in which the Tractatus is mentioned and in which a philosophical view is criticized) is mentioning a relevant commitment. Sometimes what is at issue are philosophical commitments that pertain to the Tractatus in that they figure centrally in that work, but already figure in that work only as intended targets of clarification. Sometimes what is at issue in such passages is a discussion of what, by Wittgenstein's later lights, is wrong-headed or inadequate in the Tractarian approach to criticizing the view in question. In other cases, what is at issue is something Wittgenstein earlier thought, but not necessarily at the time of having completed the Tractatus. Some of the passages our critics adduce arguably involve doctrines held by the very early Wittgenstein, before he turns on his earlier (comparatively Russellian) self in the Tractatus. (It is therefore crucial, in handling such passages, to be sensitive to the possibility of differences between the early Early Wittgenstein and the later Early Wittgenstein.) Sometimes what is at issue, in passages in the later work in which Wittgenstein criticizes what he 'earlier' thought, are views that he held when he returned to philosophy in 1929 and shortly thereafter. What is certainly at issue in at least some (and sometimes all) of the passages in such collections of 
external 'evidence' are discussions of the sorts of commitment that resolute readers can (and, indeed, often do hold) that later Wittgenstein wishes to criticize as commitments undertaken by the author of the Tractatus. But, as we have just argued above, the existence of such passages is no embarrassment to a resolute reading, as such. Any case mounted against resolute readings must therefore rest on actual readings of the passages in question: on accounts of why the passages in question should discomfit resolute readers and on assessments of the merits of such readings over the available alternatives that resolute readers can (in many cases quite easily) bring to bear on such passages. Finally, in most cases, it will matter here which resolute reading is at issue; for, as our previous note about the possibility of Jacobin readings indicates, resolute readers can and often do differ amongst themselves about when and how Wittgenstein, in his later writings, is concerned to criticize the Tractatus.

\section{References}

Anscombe, Elizabeth (1963) An Introduction to Wittgenstein's Tractatus, London: Hutchinson. Cavell, Stanley (1976) 'Knowing and Acknowledging' in S. Cavell, Must We Mean What We Say? and Other Essays, Cambridge: Cambridge University Press.

Conant, James (1992) 'The Search for Logically Alien Thought' in The Philosophy of Hilary Putnam, Philosophical Topics 20, pp. 115-80.

Conant, James (2002) 'The Method of the Tractatus' in Erich Reck (ed.) From Frege to Wittgenstein: Perspectives in Early Analytic Philosophy, Oxford: Oxford University Press, pp. 374462.

Conant, James (2003) 'On Going the Bloody Hard Way in Philosophy' in John Whittaker (ed.) The Possibilities of Sense, New York: Macmillan.

Conant, James (2004) 'What "Ethics" in the Tractatus is Not' in D. Z. Phillips (ed.) Wittgenstein on Ethics and Religion, Aldershot: Ashgate.

Diamond, C. (1991) The Realistic Spirit, Cambridge, MA: MIT Press.

Diamond, C. (2000) 'Ethics, Imagination, and the Method of Wittgenstein's Tractatus' in Alice Crary and Rupert Read (eds) The New Wittgenstein, London: Routledge, pp. 149-73.

Diamond, C. (forthcoming A) 'The Hardness of the Soft: Wittgenstein's Early Thought about Skepticism' in J. Conant and A. Kern (eds) Skepticism in Context.

Diamond, C. (forthcoming B) 'Inheriting from Frege: The Work of Reception, as Wittgenstein Did It' in Thomas Ricketts (ed.) The Cambridge Companion to Frege, Cambridge: Cambridge University Press.

Diamond, C. (forthcoming C) 'Saying and Showing: An Example from Anscombe' in Barry Stocker (ed.) Post-Analytic Tractatus: A Critical Reader, Aldershot: Ashgate.

Diamond, C. (forthcoming D) 'Criss-cross Philosophy' in E. Ammereller and E. Fischer (eds) Wittgenstein at Work, London: Routledge.

Floyd, Juliet (2002) 'Number and Ascriptions of Number in Wittgenstein's Tractatus' in Erich Reck (ed.) From Frege to Wittgenstein: Perspectives in Early Analytic Philosophy, Oxford: Oxford University Press, pp. 308-52.

Goldfarb, Warren (1997) 'Metaphysics and Nonsense: On Cora Diamond's The Realistic Spirit', Journal of Philosophical Research 22, pp. 57-73.

Goldfarb, Warren (in preparation) 'Das Überwinden: Anti-Metaphysical Readings of the Tractatus'.

Gustafsson, Martin (2003) 'Travis, the Tractatus, and Truth-conditions' in Krister Segerberg and Rysiek Sliwinski (eds) A Philosophical Smorgasbord, Uppsala Philosophical Studies 52, Uppsala: Uppsala University, pp. 169-82. 
Kremer, Michael (2002) 'Mathematics and Meaning in the Tractatus', Philosophical Investigations 25, pp. 272-303.

Kuusela, Oskari (2003) 'Wittgenstein's Conception of Philosophy and Philosophical Method', D.Phil. thesis, Oxford University.

Kuusela, Oskari (forthcoming) 'From Metaphysics and Philosophical Theses to Grammar: Wittgenstein's Turn', Philosophical Investigations.

McGinn, Marie (1999) 'Between Metaphysics and Nonsense: The Role of Elucidation in Wittgenstein's Tractatus', Philosophical Quarterly October, pp. 491-513.

Proops, Ian (2002) 'The Tractatus on Inference and Entailment' in Erich Reck (ed.) From Frege to Wittgenstein: Perspectives on Early Analytic Philosophy, New York: Oxford University Press, pp. 283-307.

Ricketts, Thomas (1996) 'Pictures, Logic, and the Limits of Sense in Wittgenstein's Tractatus' in Hans Sluga and David G. Stern (eds) The Cambridge Companion to Wittgenstein, Cambridge: Cambridge University Press, pp. 59-99.

Sullivan, Peter (2002) 'On Trying to be Resolute: A Response to Kremer on the Tractatus', European Fournal of Philosophy 10, pp. 43-78. 